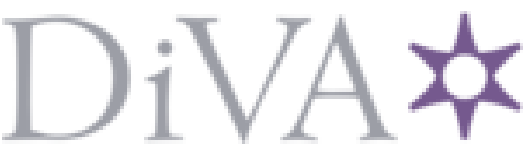

http://www.diva-portal.org

\title{
Postprint
}

This is the accepted version of a paper published in . This paper has been peer-reviewed but does not include the final publisher proof-corrections or journal pagination.

Citation for the original published paper (version of record):

Bag, P. (2018)

Pathogen-induced AdDjSKI of the wild peanut, Arachisdiogoi, potentiates tolerance of multiple stresses in E. coli andtobacco

Plant Science

https://doi.org/10.1016/j.plantsci.2018.03.033

Access to the published version may require subscription.

N.B. When citing this work, cite the original published paper.

Permanent link to this version:

http://urn.kb.se/resolve?urn=urn:nbn:se:umu:diva- 156687 


\section{Pathogen-induced AdDjSKI of the wild peanut, Arachis diogoi, potentiates tolerance of multiple stresses in $E$. coli and tobacco}

Sakshi Rampuria ${ }^{1 *}$, Pushan Bag $^{1}$, Conner J Rogan ${ }^{2}$, Akanksha Sharma ${ }^{1}$, Walter Gassmann $^{3}$, P.B Kirti ${ }^{1}$,

${ }^{1}$ Department of Plant Sciences, School of Life Sciences, University of Hyderabad, Hyderabad, Telangana, India.

${ }^{2}$ Division of Biological Sciences, Christopher S. Bond Life Sciences Center and Interdisciplinary Plant Group, University of Missouri, Columbia, MO, USA.

${ }^{3}$ Division of Plant Sciences, Christopher S. Bond Life Sciences Center and Interdisciplinary Plant Group, University of Missouri, Columbia, MO, USA.

*Correspondence: Sakshi Rampuria, Department of Plant Sciences, School of Life

Sciences, University of Hyderabad, Hyderabad, Telangana, India. Tel.: +914023134545;

Fax: +914023010120 .

\section{P.B Kirti}

pbkirti@uohyd.ac.in

\section{Highlights}

- Chloroplastic AdDjSKI enhances tolerance of E.coli against salinity, osmotic, acidic and alkaline stress conditions.

- $A d D j S K I$ over expression lines in tobacco exhibits enhanced heat, salinity, drought and osmotic stress tolerance along with enhanced disease resistance against phytopathogenic fungi $P$. parasitica pv nicotianae and S. sclerotiorum.

- $A d D j S K I$ seems to be a potential candidate for the development of stress tolerant crops, as it can protect Photosystems. 


\begin{abstract}
A gene encoding a serine-rich DnaJIII protein called AdDjSKI that has a 4Fe-4S cluster domain was found to be differentially upregulated in the wild peanut, Arachis diogoi in its resistance responses against the late leaf spot causing fungal pathogen Phaeoisariopsis personata when compared with the cultivated peanut, Arachis hypogea. AdDjSKI is induced in multiple stress conditions in A.diogoi. Recombinant E. coli cells expressing $A d D j S K I$ showed better growth kinetics when compared with vector control cells under salinity, osmotic, acidic and alkaline stress conditions. Overexpression of this type three J-protein potentiates not only abiotic stress tolerance in Nicotiana tabacum var. Samsun, but also enhances its disease resistance against the phytopathogenic fungi Phytophthora parasitica pv nicotianae and Sclerotinia sclerotiorum. In the present study we show transcriptional upregulation of $A P X, M n-S O D$ and $H S P 70$ under heat stress and increased transcripts of $P R$ genes in response to fungal infection. This transmembrane-domaincontaining $\mathrm{J}$ protein displays punctate localization in chloroplasts. AdDjSKI appears to ensure proper folding of proteins associated with the photosynthetic machinery under stress.
\end{abstract}

Key words: Arachis diogoi, AdDjSKI, DnaJ/HSP40, Multiple stress tolerance, Nicotiana tabacum var Samsun

\title{
Introduction
}

Arachis diogoi, a wild diploid species related to the cultivated peanut, is resistant to the late leaf-spot pathogen Phaeoisariopsis personata, which is one of the causative agents of a disease collectively termed as the Tikka disease in cultivated peanuts [1]. The wild relatives of cultivars of agricultural importance have always been explored for their rich and diverse gene pools. To identify paralogs responsible for biotic stress tolerance, we have developed data on differentially expressed genes and proteins present in $A$. diogoi

as compared with A. hypogea [1-3]. Previously, we characterized genes including Cyclophilin (AdCyp), Suppressor of g2 allele of skp1 (AdSGT1), Vacuolar processing enzyme (AdVPE), and serine/arginine-rich splicing factor (AdRSZ21), which have roles 
in enhancing disease resistance in the heterologous system, Nicotiana tabacum, thereby showing the rich biotic stress responsive gene pool of $A$. diogoi [1, 4-6]. In addition to the genes responsible for increasing resistance towards fungal pathogens, we have identified genes that can augment abiotic stress tolerance such as AdLEA [7], indicating that the defense response in $A$. diogoi results from molecular overlap between recognition and signaling pathways that regulate abiotic and biotic stress tolerance in plants. Upregulating defense-related transcripts to combat biotic stress is as important as ensuring proper growth and development of plants under the stress. Moreover, a plant in its natural environment is always exposed to a combination of stresses and hence, must be wellprepared to survive under such conditions. In this respect, $A$. diogoi offers a rich gene pool for exploitation.

Plants are well equipped with several antioxidant enzymes, metabolism-related enzymes, sugars and amino acids, defense-related proteins, cell-death-associated proteins, and various other stress tolerance mechanisms. Despite this, they show a varied level of tolerance: some are highly tolerant to extreme stresses occurring in nature while others are much less tolerant. Under stress conditions, a misbalance in protein homeostasis arises as a result of improperly folded proteins [8]. This leads to non-functional stresscombating molecular machinery. Chaperones play a significant role in rescuing cells under stress while maintaining protein homeostasis [9]. Accordingly plants have developed an array of molecular pathways to evade stresses by increasing the pool of molecular chaperones [10]. Molecular chaperones interact with diverse protein substrates to assist their folding and prevent accumulation of misfolded or otherwise damaged nonfunctional protein molecules. DnaJ proteins, also known as Heat shock protein 40 (HSP40), are a family of conserved co-chaperones for HSP70s [11]. DnaJ/HSP40 proteins determine the activity of HSP70s by activating ATPase and also providing them substrates to act upon [12]. They can bind both folded and unfolded protein substrates, thus promoting reactivation of proteins damaged during different stress conditions and facilitating the proteolysis of abnormal proteins [13]. 
DnaJ proteins exhibits a 70 amino acid consensus sequence known as the $\mathrm{J}$ domain, through which they interact with HSP70 proteins [12]. Based on the structural domains, DnaJ proteins can be classified into three types. Type I proteins possess a J-domain, a G/F-rich region, and a zinc finger domain. Type II have a J-domain with G/F-rich region or a zinc finger domain. Type III proteins have the J domain which may or may not be associated with another domain [14]. DnaJ proteins have been shown to be suppressors or activators of plant stress responses. The virulence effector HopI1, a chloroplast targeted class III J-protein from Pseudomonas syringae, suppresses both salicylic acid (SA) accumulation and host defense responses in Arabidopsis [15]. However, transient overexpression of a nuclear-localized type III DnaJ domain-containing HSP40 of soybean, a co-chaperone of HSP70, resulted in hypersensitive response (HR)-like cell death in leaves of Nicotiana benthamiana [16]. Induction of cell death was found to be dependent on nuclear localization of HSP40 and on the MAPKKK $\alpha$ - and WIPK (Wounding-inducible Protein Kinase)-mediated signaling pathways. The mitochondrialtargeted DnaJ family protein BIL2 has been shown to enhance resistance against salinity stress and strong light stress through the brassinosteroid signaling pathway [17]. The chloroplast-targeted DnaJ protein LeCDJ2 of tomato has been shown to reduce the accumulation of $\mathrm{O}_{2}{ }^{-}$and $\mathrm{H}_{2} \mathrm{O}_{2}$ under drought stress and enhance resistance to the bacterial pathogen Ralstonia solanacearum when overexpressed in tobacco [18]. Moreover, tomato LeCDJ1 has been shown to have essential functions in maintaining PSII under chilling stress [19]. Also, Wang et al. showed that a chloroplast-targeted SICDJ2 protein protects $\mathrm{RuBisCO}$ activity under heat stress [20]. Also, knockout mutants of three chloroplasttargeted J-proteins of A. thaliana (AtJ8, AtJ11 and AtJ20) showed decreased photosynthetic efficiency, destabilization of PSII complexes and loss of control for balancing chloroplast redox reactions [21].

In the present investigation, we have characterized a pathogen-induced type III DnaJ protein-encoding gene from $A$. diogoi, AdDjSKI, and studied the effect of its ectopic expression in transgenic tobacco against biotic and abiotic stresses. AdDjSKI is different from the previously studied chloroplast-targeted type III J-proteins (Table 1) as it has a ferredoxin (4Fe-4S) domain associated with the N-terminal J-domain which was absent 
in earlier reported J-proteins. The $4 \mathrm{Fe}-4 \mathrm{~S}$ domain was reported to be involved in electron transfer reactions and redox functions, and was also shown to be involved in the control of gene expression, DNA damage recognition and repair, and cellular responses to oxidative stress [22]. Previously, chloroplast-resident type III J-proteins having a ferredoxin domain, for example the CDJ3 and CDJ4 proteins of Chlamydomonas reinhardtii, have been shown to interact with ATP-bound HSP70B as dimers [23]. However, these proteins have not been characterized under stress conditions in plants. AdDjSKI shows only $40.8 \%$ and $32.7 \%$ homology with CDJ3 and CDJ4, respectively [23]. In this report, we characterize changes in gene expression and phenotypes associated with the overexpression of AdDjSKI under different stress conditions.

\section{Materials and methods}

\section{RACE PCR, isolation of full-length cDNA and phylogenetic tree construction}

A transcript-derived fragment of $A d D j S K I$ was identified in an earlier study of differential gene expression using cDNA-AFLP in Arachis diogoi, a wild relative of cultivated peanut challenged with the late leaf-spot pathogen, $P$. personata [3]. The full gene sequence of this gene was determined through rapid amplification of cDNA ends (RACE) following SMART $^{\mathrm{TM}}$ RACE cDNA Amplification kit (Clontech, Takara Biotech, Japan) manufacturer instructions. Gene specific primers used for 5'/3' RACE-PCR are 5'TCCCACATTGGCTATATACCCTAG-3' and 5'GAATGGGAGGAGCGTCATTCG-3', respectively. RACE products were cloned into T/A vector, pTZ57R/T (Fermentas, Lithuania, EU) and sequenced commercially (Eurofins Genomics India Private Limited, Bangalore, India). The full-length cDNA sequence of $A d D j S K I$ was obtained by aligning 5'/3' RACE products with the EST sequence identified in the cDNA-AFLP study. A phylogenetic tree with different types of DnaJ-protein was made to classify AdDjSKI as a type III J protein using neighbor-joining algorithms of MEGA 4.0 software after fulllength protein sequence alignment using the ClustalW program [24]. Bootstrapping was performed to obtain support values for each branch and ExPASy's prosite [25] was used to determine conserved domains. 


\section{Hormonal treatments and collection of samples for analysis of $A d D j S K I$ expression by RT-qPCR}

Twigs of wild peanut plants (A.diogoi) cut in the internodal region were kept in a tray with moist cotton saturated with sterile distilled water wrapped around the base of twigs and the tray was covered with a polythene sheet to maintain humidity. This treatment stabilizes the twigs with adventitious root formation as described previously [1]. These rooted twigs were utilized in the studies of $A d D j S K I$ expression in various treatments: 100 $\mu \mathrm{M}$ salicylic acid (SA), $100 \mu \mathrm{M}$ methyl jasmonate (MeJA), $100 \mu \mathrm{M}$ abscisic acid (ABA), $250 \mu \mathrm{M}$ ethephone, $200 \mathrm{mM}$ sorbitol, $10 \mathrm{mM} \mathrm{H}_{2} \mathrm{O}_{2}, 100 \mu \mathrm{M}$ sodium nitroprusside (SNP), $100 \mathrm{mM} \mathrm{NaCl}, 10 \%$ (w/v) polyethylene glycol (PEG-MW6000), $10 \mu \mathrm{M}$ methyl viologen (MV) and heat shock at $42{ }^{\circ} \mathrm{C}$ along with treatment with water, which served as control. The treatments were performed for $24 \mathrm{hr}$ in a time-course in the culture room at $27 \pm 1$ ${ }^{\circ} \mathrm{C}$ under a 14/10 hr photoperiod with a light intensity of $30 \mu \mathrm{mol} / \mathrm{m}^{2} / \mathrm{s}$. For each experiment, 3-4 leaves from different twigs representing one sample were collected at regular intervals, quick frozen in liquid nitrogen, and stored at $-80{ }^{\circ} \mathrm{C}$ until use. Samples from three independent experiments were collected for RT-qPCR analysis.

\section{Total RNA isolation and RT-qPCR}

Total RNA from control and treated peanut samples was extracted [26] and treated with RNase-free DNase1 (Sigma-Aldrich, USA). The quality of the isolated RNA was checked on a gel and subsequently quantified. $2 \mu \mathrm{g}$ of total RNA was reverse transcribed with oligo-dT (18 mer) using SMART ${ }^{\text {тм }}$ MMLV Reverse Transcriptase (Clontech, Takara Biotech, Japan). First-strand cDNA samples were diluted $2.5 \mathrm{X}$ and $1 \mu$ of the diluted reaction mixture was used as RT-qPCR template in a $20 \mu$ l total reaction volume containing $0.4 \mu \mathrm{M}$ gene-specific primers and $10 \mu \mathrm{l}$ SYBR Premix Ex Taq with ROX (Takara Bio INC., Japan). The samples were appraised in three technical replicates including no-template and no-RT negative controls for each experiment. PCR analysis was carried out in a Realplex (Eppendorf, Germany) amplifier with the following cycle parameters: $95{ }^{\circ} \mathrm{C}$ for $5 \mathrm{~min} ; 40$ cycles of $95^{\circ} \mathrm{C}$ for $20 \mathrm{~s}, 58^{\circ} \mathrm{C}$ for $20 \mathrm{~s}, 72{ }^{\circ} \mathrm{C}$ for $30 \mathrm{~s}$ followed by a melting curve to ensure that each amplicon is a single product. Alcohol dehydrogenase class III $(A D H 3)$ and ubiquitin (UBI1) genes were used as the internal 
controls to normalize the real time amplification data [27]. Relative fold change in RNA expression was estimated using the $\Delta \Delta \mathrm{C}_{\mathrm{T}}$ method [28]. Primer sequences used are listed in table S1. Data were plotted from three independent experiments as mean \pm SD. Statistical analysis of variance (one-way ANOVA) was performed by SIGMA PLOT ver. 11.0 (St.Louis, MO, USA). Asterisks represent a significant difference from the untreated counterpart $(P<0.05)$.

\section{Subcellular localization of AdDjSKI}

$A d D j S K I$ CDS was cloned in binary vector pDOE15 [29] using CpoI and AatII as restriction sites in forward and reverse primer, respectively (Table S1). Subcellular localization of AdDjSKI protein fused with C-terminal mVenus tag was determined by its transient expression in Nicotiana benthamiana plants [30]. Hc-Pro as silencing suppressor and RFP were co-expressed to identify the cell cytoplasm and the nucleus. Agrobacterium strain C58C1 was grown overnight in LB medium containing tetracycline $(5 \mu \mathrm{g} / \mathrm{ml})$ and kanamycin $(50 \mu \mathrm{g} / \mathrm{ml})$. Cultures were pelleted and resuspended in equal volumes of induction medium (10 $\mathrm{mM} \mathrm{MgCl}_{2}, 10 \mathrm{mM}$ MES pH 5.6) containing $150 \mu \mathrm{M}$ acetosyringone (Sigma, St. Louis, MO) for 3-4 hr at room temperature in dark. Desired agrobacterium cultures were combined to a final absorbance $(600 \mathrm{nM})$ of 0.2 for each strain. The bacterial suspension was infiltrated into leaves of four-week-old $N$. benthamiana plant by routine procedures and infiltrated areas were viewed under a Zeiss LSM 510 META NLO two-photon-scanning confocal microscope with a 40X water objective after two days. Expression of AdDjSKI protein was later confirmed through western blotting using Anti-GFP antibody and this experiment was performed twice.

\section{Heterologous expression of $A d D j S K I$ in $E$. coli strain BL21(DE3)}

$A d D j S K I$ was amplified with primers incorporating NcoI and HindIII as restriction sites in forward primer and reverse primer, respectively, and was subsequently cloned into the bacterial expression vector pET32a. Recombinant vector (pET32a: AdDjSKI) and pET32a were mobilized to E. coli strain BL21(DE3) and colonies were confirmed through colony PCR post transformation. Secondary culture of BL21 cells harboring the control and recombinant vector were grown in Luria-Bertani (LB) broth supplemented with 
ampicillin $(100 \mu \mathrm{g} / \mathrm{mL})$ to an $\mathrm{OD}_{600}$ of $0.5-0.6$, after which IPTG was added to a final concentration of $1.0 \mathrm{mM}$ to induce the expression of target protein in recombinant $E$. coli cells. After $3 \mathrm{hr}$ of induction, cells were centrifuged, resuspended in 1X PBS buffer (300 $\mathrm{mM} \mathrm{NaCl}, 50 \mathrm{mM} \mathrm{Na}_{2} \mathrm{HPO}_{4}$,) and 1X SDS-PAGE sample loading buffer. Overexpression of AdDjSKI was checked on 12\% SDS-PAGE gel.

\section{Spot assay for abiotic stress tolerance of $E$. coli BL21 (DE3) transformants}

Abiotic stress tolerance of BL21/AdDjSKI and BL21/pET32a were analyzed under $\mathrm{NaCl}$ (400 mM and $500 \mathrm{mM}$ ), sorbitol (500 mM and $700 \mathrm{mM}$ ), pH 9 and $\mathrm{pH} 5$ stress conditions in E. coli. Secondary cultures of BL21/AdDjSKI and BL21/pET32a grown to an $\mathrm{OD}_{600}$ of 0.5-0.6 were serially diluted up to $5 \log$ dilutions and $2.5 \mu \mathrm{l}$ of each dilution was spotted on Luria-Bertani agar (LB agar) medium containing IPTG (1 mM) and different stress conditions described above. Cells were allowed to grow overnight at $37{ }^{\circ} \mathrm{C}$ after which observations were made. Spot assays were performed in duplicates for three independent experimental repeats, taking fresh transformants each time.

\section{Measurement of cell density under abiotic stress}

Secondary cultures of BL21/AdDjSKI and BL21/pET32a were grown to an $\mathrm{OD}_{600}$ of 1 at $37{ }^{\circ} \mathrm{C}$ in an incubator-shaker (Orbitek, Scigenics, Tamil Nadu, India). A small amount of this culture equivalent to an $\mathrm{OD}_{600}$ of 0.1 was added to $100 \mathrm{ml}$ of $\mathrm{LB}$ broth containing IPTG (1.0 mM) together with different stress conditions $(\mathrm{NaCl} 400 \mathrm{mM}, \mathrm{NaCl} 500 \mathrm{mM}$, sorbitol $500 \mathrm{mM}$, sorbitol $700 \mathrm{mM}$, pH 7, pH 5 and pH 9). Cells were allowed to grow in an incubator shaker at $37{ }^{\circ} \mathrm{C}$ and growth of cells was measured in terms of $\mathrm{OD}_{600}$ at $1 \mathrm{hr}$ intervals for $9 \mathrm{hr}$. Data plotted are means \pm SD from three independent experiments performed using fresh transformants each time.

\section{Vector construction and Agrobacterium-mediated genetic transformation in tobacco} and analysis of transgenic tobacco plants

The open reading frame of $A d D j S K I$ was amplified using Phusion ${ }^{\mathrm{TM}}$ high-fidelity DNA polymerase (Finnzymes, NEB, UK) with primers incorporating the restriction sites NcoI and $S m a \mathrm{I}$ in forward primer and reverse primer, respectively (Table S1). This amplified 
PCR product was sequenced commercially for the confirmation of the reading frame. The ORF of $A d D j S K I$ was cloned at the NcoI-SmaI site into the plant expression cassette of pRT100 vector [31]. The AdDjSKI expression cassette containing the CaMV-35S promoter and the termination signal was released with Pst $\mathrm{I}$ digestion and was subsequently cloned in the binary vector pCAMBIA2300 [32] at the PstI restriction site.

The recombinant binary vector was mobilized into the Agrobacterium strain LBA4404 by the freeze-thaw method [33]. A single colony of Agrobacterium carrying the recombinant binary vector was inoculated in LB broth containing rifampicin $(25 \mu \mathrm{g} / \mathrm{ml})$ and kanamycin $(50 \mu \mathrm{g} / \mathrm{ml})$. Secondary culture with bacterial OD $0.6-0.8$ was used to transform tobacco variety Samsun using the standard leaf disc method [34]. The Agrobacterium treated leaf discs were cultured on regeneration medium containing MS medium supplemented with $2 \mathrm{mg} / 1$ benzyl aminopurine (BAP), $0.1 \mathrm{mg} / 1$ naphthalene acetic acid (NAA), $250 \mathrm{mg} / 1$ cefotaxime and $125 \mathrm{mg} / 1 \mathrm{kanamycin}$, and twice were subcultured after 12-15 d. Healthy kanamycin-resistant elongated shoots of 4-5 cm length were cut out and cultured on a rooting medium containing MS medium supplemented with $1 \mathrm{mg} / 1 \mathrm{NAA}, 250 \mathrm{mg} / \mathrm{l}$ cefotaxime and $125 \mathrm{mg} / \mathrm{l}$ kanamycin for $12-15 \mathrm{~d}$. Plantlets were acclimatized under culture room conditions, transferred to soil and grown to maturity in the greenhouse. The $\mathrm{T}_{1}$ seeds from the primary transgenic $\left(\mathrm{T}_{0}\right)$ plants obtained through tissue culture were collected and were germinated on MS selection medium containing $125 \mathrm{mg} / \mathrm{l}$ kanamycin to select and discriminate the transgenic $\mathrm{T}_{1}$ seedlings from the null segregants. $T_{1}$ seeds of 8 different independent plants were subjected to the analysis for resistance to the marker gene related antibiotic, kanamycin for the identification of lines with single gene inheritance. Around 50-100 seeds of each plant were spread on kanamycin (125 mg/l)-containing $1 / 2 \mathrm{MS}$ media and the numbers of resistant vs sensitive seedlings were recorded. Transgenic lines showing single locus insertion (3:1 segregation) as revealed by $\chi^{2}$ test (Table S2) were further raised to $\mathrm{T}_{2}$ generation. Seeds were collected from 10-12 different kanamycin resistant progeny plants from each of the primary transgenic plants and were checked for their homozygosity. Homozygous lines in the $\mathrm{T}_{2}$ generation were identified by $100 \%$ germination on the kanamycin selection medium and were used for experimental purposes. 


\section{Molecular screening of transgenic tobacco plants}

DNA was isolated from acclimatized $T_{0}, T_{1}$ and $T_{2}$ transgenic plants using the CTAB method [35] and around $50 \mathrm{ng}$ of DNA was used in PCR amplifications. Putative transgenic plants were screened by amplifying the genomic DNA with nptII and the gene specific $(A d D j S K I)$ forward and reverse primers. For RNA isolation, about $100 \mathrm{mg}$ of fresh leaf tissue was ground with a mortar and pestle to fine powder in liquid nitrogen. Total RNA was extracted using TRI-reagent (Sigma-Aldrich, USA) followed by DNase treatment (Fermentas, Lithuania). Isolated RNA was checked on gels, quantified and used to analyze the expression of $A d D j S K I$ in transgenic tobacco plants by semi-quantitative RT-PCR, taking actin as the internal control.

\section{Heat-stress tolerance assay and RT-qPCR analysis of stress-related genes post heat stress}

Fifteen-day-old seedlings of WT and transgenic lines \#19, \#22 and \#25 were transplanted and grown in plastic cups containing an equal weight of soil mixture (soilrite: soil =1:4) and were watered on alternate days under controlled conditions in a growth chamber (Orbitek, Scigenics, Tamil Nadu, India) at $26{ }^{\circ} \mathrm{C}, 70 \%$ humidity for $15-20 \mathrm{~d}$. The temperature of the growth chamber was gradually increased to $46{ }^{\circ} \mathrm{C}$ for $2 \mathrm{hr}$ [36] and wilting phenotypes were recorded post heat-stress treatment. Subsequently, the temperature of the growth chamber was gradually decreased to $26{ }^{\circ} \mathrm{C}$ and the treated plants were observed for recovery of growth for one week. Two independent experiments were performed with three plants per line in each experiment for phenotypic observations.

For RT-qPCR analysis, plants were subjected to heat stress of $42{ }^{\circ} \mathrm{C}$ and leaves of two plants per line were collected after $0 \mathrm{~min}$ and $30 \mathrm{~min}$ of treatment per sample. Expression of genes encoding oxidative-stress-related enzymes, HSP70 variants, metabolism and drought-stress-related proteins was quantitatively evaluated using actin as internal standard. Real-time PCR amplifications were carried out in a Realplex (Eppendorf, Germany) amplifier under the following cycle parameters; $95^{\circ} \mathrm{C}$ for $2 \mathrm{~min}$; 40 cycles of $95{ }^{\circ} \mathrm{C}$ for $15 \mathrm{~s}, 57^{\circ} \mathrm{C}$ for $20 \mathrm{~s}, 72^{\circ} \mathrm{C}$ for $20 \mathrm{~s}$ followed by a melting curve to ensure that 
each amplicon is a single product. Relative fold change in RNA expression was estimated using the $\Delta \Delta \mathrm{C}_{\mathrm{T}}$ method [28]. Primer sequences used are listed in Table $\mathrm{S} 1$. Data as mean $\pm \mathrm{SD}$ are plotted from three independent experiments with two plants per line in each experiment. Statistical analysis of variance (one-way ANOVA) was performed by SIGMA PLOT ver. 11.0 (St.Louis, MO, USA). Asterisks represent a significant difference from the untreated counterpart $(P<0.05)$.

\section{Seedling assay for abiotic stress tolerance}

Seeds of WT and transgenic lines (\#19, \#22 and \#25) were collected in a micro-centrifuge tube, washed for $1 \mathrm{~min}$ with $75 \%$ ethanol, and then with water. Subsequently, the seeds were surface-sterilized with $2 \%(\mathrm{v} / \mathrm{v})$ sodium hypochlorite for $10 \mathrm{~min}$ in a microcentrifuge tube, washed with sterile distilled water 5-6 times, and germinated on halfstrength MS medium without organic compounds. The seedlings were maintained in a culture room at $27^{\circ} \mathrm{C}$ with a photoperiod of $16 \mathrm{hr}$ light and $8 \mathrm{hr}$ dark. For $\mathrm{NaCl}$ stress, the seedlings were transferred to $1 / 2$ MS media containing 100, 150, 200 and $300 \mathrm{mM} \mathrm{NaCl}$. The percentage survival of the seedlings after stress on $200 \mathrm{mM} \mathrm{NaCl}$ containing $1 / 2 \mathrm{MS}$ media was calculated from three experimental repeats. For biochemical assay eleven seedlings per experiment were used for biochemical assays. Total chlorophyll content was estimated spectrophotometrically after extraction of fresh material (200 $\mathrm{mg})$ in dimethyl sulphoxide (DMSO) according to Hiscox and Israelstam [37]. Lipid peroxidation levels were estimated by measuring the thiobarbituric acid reactive substance (TBARS) [38]. Similar treatments given to seedlings were with PEG MW 6000 (7\%), mannitol (100 mM) and sorbitol (200 mM). Root length, fresh weight, turgid weight and dry weight of 11 seedlings per experiment were measured $20 \mathrm{~d}$ after the initiation of the corresponding treatment. Data plotted from three independent experiments are means $\pm \mathrm{SD}$. Statistical analysis of variance (one-way ANOVA) was performed by SIGMA PLOT ver. 11.0 (St. Louis, MO, USA). Asterisks represent a significant difference from the untreated seedlings $(P<0.05)$.

\section{Detection of ROS using confocal microscopy}


Epidermal peels of WT and transgenic tobacco lines were treated with $\mathrm{H}_{2}$ DCFDA as described by Konopka-Postupolska et al. 2009 [39]. After washing the excess dye from the peels, $\mathrm{NaCl}$ stress-induced ROS formation was determined in the guard cells by incubating the epidermal peels in $100 \mathrm{mM} \mathrm{NaCl}$ for another $30 \mathrm{~min}$. A control experiment was also performed in parallel with a mock treatment of buffer to detect the basal levels of ROS in the guard cells of the WT and transgenic tobacco plants. The fluorescence $\left(\lambda_{\text {ex }}\right.$ $488 \mathrm{~nm}$ and $\lambda_{\mathrm{em}}-530 \mathrm{~nm}$ ) was visualized by using a Leica Laser Scanning Confocal Microscope (Leica, TCS-SP2 with AOBS, Heidelberg, GmbH, Germany) and the experiment was repeated thrice with at least $n=60$ stomata for each plant line in one experiment. Quantification of fluorescence was done by selecting equal areas of pigmentation using Image-J 1.42 software (NIH, USA). The mean \pm SD values are plotted in a bar diagram. Statistical analysis of variance (one-way ANOVA) was performed by SIGMA PLOT ver. 11.0 (St.Louis, MO, USA). Asterisks represent a significant difference of fluorescence from the stomata of untreated epidermal peel $(P<0.001)$.

\section{AdDjSKI transgenic tobacco plant resistance to phytopathogenic fungal pathogens}

Detached leaf assays were performed to analyze the disease resistance response of the $\mathrm{T}_{2}$ generation of $A d D j S K I$ transgenic plants against the fungal pathogens Phytophthora parasitica var. nicotiana and Sclerotinia sclerotiorum. The fungi were grown on potato dextrose agar (PDA) (Himedia, India) for 5-7 days at $24^{\circ} \mathrm{C}$. Fully expanded leaves of two-month-old plants of wild type (WT) and transgenic plants were placed on moist filter paper for fungal inoculation. A $0.5 \mathrm{~cm}$ diameter gel plug from a plate of $P$. parasitica var. nicotianae or S. sclerotiorum carrying the fungal mycelium grown on PDA was placed on the middle region of the adaxial side of leaf after abrading the leaf with a sterile blade to promote fungal infection [40]. The leaves were placed in the growth room with $16 \mathrm{hr} / 8$ hr light:dark photoperiod. Leaf damage and symptoms were recorded 3-7 days post infection (dpi). This experiment was performed with three leaves per line from three different plants. Data plotted from three independent experiments are means \pm SD.

\section{RT-qPCR analysis of defense related genes post infection with $P$. parasitica var. nicotianae}


Detached leaf assays were performed according to Tedford et al. [40]. Two leaf samples per line collected $24 \mathrm{hr}$ post infection with $P$. parasitica var. nicotianae and two untreated control leaves detached and wounded for $24 \mathrm{hr}$ were considered as treatment samples in each experiment for isolating total RNA. Expression of transcripts of $P R$ and HR-related genes such as Patatin-like phospholipase 3 (PAT3), Harpin-induced gene (HIN1) and Hyper-sensitive-related gene (HSR203J) was quantitatively evaluated using actin as internal standard. Real-time PCR amplifications were carried out in a Realplex (Eppendorf, Germany) amplifier under the following cycle parameters; $95^{\circ} \mathrm{C}$ for $2 \mathrm{~min}$; 40 cycle of $95{ }^{\circ} \mathrm{C}$ for $15 \mathrm{~s}, 58^{\circ} \mathrm{C}$ for $20 \mathrm{~s}, 72^{\circ} \mathrm{C}$ for $20 \mathrm{~s}$ followed by a melting curve to ensure that each amplicon is a single product. Relative fold change in RNA expression was estimated using the $\Delta \Delta \mathrm{C}_{\mathrm{T}}$ method [28]. Primer sequences used are listed in Table $\mathrm{S} 1$. Data were plotted from three independent experiments mean \pm SD. Statistical analysis of variance (one-way ANOVA) was performed by SIGMA PLOT ver. 11.0 (St.Louis, MO, USA). Asterisks represent a significant difference from the control, i.e. $24 \mathrm{hr}$ detached and wounded leaf $(P<0.05)$.

\section{DNA extraction and quantification of fungal biomass in infected tissues}

Genomic DNA was isolated from fungus as well as from $200 \mathrm{mg}$ infected tissues of wild type and transgenic lines [41]. Samples were collected from two plants per line in one representative experiment. Primers were designed from an internal transcribed spacer (ITS) region of the 5.8S rDNA of fungus (Table S1). RNase-treated DNA was quantified spectrophotometrically and its integrity was checked on an agarose gel. Standard curves based on threshold cycle (CT) for $10^{5}$-fold dilutions of fungal genomic DNA were constructed for P. parasitica var. nicotianae [5] and S. sclerotiorum. For quantitative determination of fungal biomass in the infected tissues of WT and transgenic plants, standard curves were plotted using $10^{5}$-fold dilutions of fungal genomic DNA of $S$. sclerotiorum with 0.997 as the regression coefficient $\left(\mathrm{r}^{2}\right)$. Regression coefficient was determined by absolute quantification against known concentrations of fungal DNA. Real-time PCR amplification was carried out (Eppendorf, Germany) under following cycle parameters: $95{ }^{\circ} \mathrm{C}$ for $2 \mathrm{~min}, 40$ cycles of $95{ }^{\circ} \mathrm{C}$ for $15 \mathrm{~s}, 58{ }^{\circ} \mathrm{C}$ for $20 \mathrm{~s}, 70{ }^{\circ} \mathrm{C}$ for $20 \mathrm{~s}$ followed by melting curve analysis. Based on the standard curves, concentrations of 
fungal DNA per $200 \mathrm{ng}$ of DNA isolated from infected plant tissue (a square of $2 \mathrm{~cm} \times 2$ $\mathrm{cm}$ was cut next to the site of infection) were calculated. Data were plotted from three independent experiments mean $\pm \mathrm{SD}$. Statistical analysis of variance (one-way ANOVA) was performed by SIGMA PLOT ver. 11.0 (St.Louis, MO, USA); asterisks represent a significant difference from the susceptible counterpart $(P<0.05)$.

\section{Results}

\section{AdDjSKI is a chloroplastic type III DnaJ protein}

Wild peanut, $A$. diogoi, exhibits enhanced resistance against multiple stresses. In order to identify potentially useful resistance genes, we performed a cDNA-AFLP analysis with A.diogoi challenged with the late leaf-spot pathogen, P. personata [3]. AdDjSKI (KJ658279) was obtained by aligning 5'/3' RACE products (Fig. 1A and B). The predicted AdDjSKI protein has one 4Fe-4S (163-191 aa) cluster domain along with the J-domain (80-145 aa), and the cysteine-rich (CS) region and zinc finger domain are absent, a characteristic of type III DnaJ proteins (Fig. 1C). AdDjSKI is predicted to be localized in the plastid by IPSORT [42], Predotar [43] and targetP1.1 [44] with high confidence. In order to examine whether AdDjSKI is localized in plastids, we tagged AdDjSKI with mVenus at the C-terminus and transiently expressed it in N.benthamiana. Expression of the protein was confirmed with anti-GFP antibody on western blot (Fig. S1). As shown in Fig. 1D, AdDjSKI localized as punctate spots in chloroplasts, suggesting that it is present in either thylakoid membranes or in stroma lamellae. This ferredoxin containing membrane bound J-protein not only seems to be required for maintaining the photosynthetic machinery of plants under stress conditions, but could also measure and regulate the redox state of the cell.

\section{Heterologous expression of $A d D j S K I$ enhanced abiotic stress tolerance of $E$. coli BL21(DE3) cells}

We confirmed overexpression of AdDjSKI protein in E. coli BL21(DE3) on $10 \%$ SDSPAGE gel at $2 \mathrm{hr}$ and $3 \mathrm{hr}$ post IPTG $(1 \mathrm{mM})$ induction (Fig. S2). Cells carrying 
recombinant vector pET32a:AdDjSKI had increased tolerance to abiotic stress conditions including salinity stress, osmotic stress and stress due to acidic and alkaline conditions ( $\mathrm{pH} 5$ and $\mathrm{pH}$ 9) compared to cells containing the empty vector. The viability of $A d D j S K I-$ expressing cells in spot assays was greater than that of control cells under all the stress conditions studied (Fig. 2A). Correspondingly, control cells showed retardation of growth rate under the stress conditions as compared to $A d D j S K I$-expressing cells (Fig. 2B-D). Interestingly, E. coli has no paralogues of AdDjSKI; yet, overexpression of this protein in the prokaryotic system increased its abiotic stress tolerance. It appears that the chaperonin function of this J-protein is not restricted to organelles of eukaryotes; it can also activate and provide clients to DnaK (HSP70) of prokaryotic origin.

\section{Expression of $A d D j S K I$ is highly responsive to multiple stresses in $\boldsymbol{A}$. $\operatorname{diogoi}$}

Transcript levels of $A d D j S K I$ in $A$. diogoi were observed to be upregulated in response to different hormonal and chemical treatments at various time points. Expression was increased by a variety of stress treatments; however, expression was most strongly induced by $24 \mathrm{hr}$ of treatments with sorbitol and salicylic acid (Fig. 3). AdDjSKI expression was incrementally induced under sodium nitroprusside (SNP) and ethephon treatment during the time course of the experiment, suggesting its possible involvement in nitric oxide and ethylene-related pathways. The eight-fold increase in expression during the early hours ( $3 \mathrm{hr}$ ) of treatment with methyl jasmonate (MeJA) was reduced by half in the later stages of treatment. Significant upregulation was not observed during early time points of ABA treatment. SA- and MeJA-associated molecular pathways work antagonistically to each other; since biogenesis of these hormones also occurs in chloroplasts, it is interesting to observe that expression of $A d D j S K I$ gets upregulated to comparable levels after only $3 \mathrm{hr}$ treatment with SA and MeJA. The increased expression of AdDjSKI during MeJA, salicylic acid (SA), ethephon and SNP treatments suggests it is involved in an interconnected signaling network. However, expression level increases under ethephon and SNP treatments reach approximately 8 fold only at the $12 \mathrm{hr}$ time point, which is a delayed response compared to the response at $3 \mathrm{hr}$ after MeJA and SA treatments. This suggests a possible role of AdDjSKI in wound signaling and systemic 
acquired resistance (SAR), as its transcript levels are responsive to an increase in SA and JA hormones.

Significant increases in $A d D j S K I$ expression levels were observed at different time points under $\mathrm{NaCl}, \mathrm{H}_{2} \mathrm{O}_{2}$, PEG and MV treatments, where its expression reached as high as 20fold $12 \mathrm{hr}$ post $\mathrm{NaCl}$ treatment. Under osmotic stress caused by sorbitol, expression levels of this gene were increased up to 50 fold by $24 \mathrm{hr}$. It was interesting to see transcriptional upregulation of $A d D j S K I$ to almost 8 fold during $24 \mathrm{hr}$ of $\mathrm{H}_{2} \mathrm{O}_{2}$, PEG and MV treatments of the twigs, which suggests that these transcripts are responsive to ROS accumulation in cells. Moreover, this change in transcript level observed for AdDjSKI could be part of a general stress response. Interestingly, its expression was upregulated within just 5 min treatment of heat stress and increased much more from $15 \mathrm{~min}$ to $1 \mathrm{hr}$ time points, hinting that the DnaJ genes are probably the first among the chaperones that are induced with increased temperature. These expression profiles suggest that the expression of AdDjSKI in $A$. diogoi is not influenced by a particular type of stress signal, but is induced during stress irrespective of its type (Fig. 3).

\section{Generation of $A d D j S K I$ transgenic overexpression lines}

$A d D j S K I$ overexpressing transgenic tobacco plants were generated in N. tabacum var. Samsun by using the constitutive CaMV 35S promoter. Plantlets generated through tissue culture were screened by PCR based amplification of the antibiotic selection marker gene, nptII (Fig. S3) and AdDjSKI using gene specific primers (Fig. S4). High and low expression plants were identified among independent $\mathrm{T}_{0}$ transgenic plants by studying expression of $A d D j S K I$ through semi-quantitative RT-PCR using actin as an internal standard. Plant \#19 showed low expression, while \#9, \#11, \#17, \#22, \#25 and others showed high expression of $A d D j S K I$ (Fig. S5). We selected plants \#19, \#22 and \#25 for further analysis taking untransformed WT plants as reference for abiotic and biotic stress assays. The primary transgenic plants were grown to maturity in the green house and the selfed seed was analyzed by the segregation of kanamycin resistance in $\mathrm{T}_{1}$ plants. Singlelocus transgenic lines identified (Table S2) were carried to the $\mathrm{T}_{2}$ generation. All analyses were carried out on $\mathrm{T}_{2}$ homozygous plants. 


\section{Abiotic stress: Overexpression lines showed enhanced heat, salinity, osmotic and drought stress tolerance}

Plants growing under controlled conditions in a growth chamber $\left(26^{\circ} \mathrm{C}, 70 \%\right.$ humidity $)$ were exposed to a gradual increase in temperature to $45^{\circ} \mathrm{C}$. WT plants showed symptoms of severe wilting after $2 \mathrm{~h}$ of treatment and were completely wilted after $3 \mathrm{hr}$ of treatment, while the high expression lines \#22 and \#25 remained healthy (Fig. 4A, B). Though the low expression line \#19 exhibited some wilting, the top crown of leaves looked healthy. After the heat stress treatment, the temperature of the growth chamber was gradually reduced to $26^{\circ} \mathrm{C}$ and the treated plants were observed for recovery and growth for one week. Old leaves of high expression lines, \#22, \#25 showed some chlorosis indicating heat damage. However, these plants resumed normal growth. The old leaves of \#19 were also damaged, but WT plant leaves became bleached and wilted, signifying severe damage resulting from the heat stress treatment (Fig. 4C). WT plants were not able to recover and resume growth even two weeks after the heat stress treatment.

We gave a milder heat stress treatment to WT and transgenic lines at $42{ }^{\circ} \mathrm{C}$ for $30 \mathrm{~min}$ and studied the relative gene expression levels of tobacco genes associated with oxidative stress, osmotic stress and drought stress. We observed that the expression of Ascorbate peroxidase (APX), Mn-superoxide dismutase (Mn-SOD), Sucrose synthase, HSP 70, HSP 70-2 and HSP 70-3 was significantly upregulated in transgenic lines, unlike WT (Fig. 4D). No significant changes in the expression levels of catalase, drought responsive element binding protein (DREB), early response to dehydration 10d (ERD10d), and ethylene responsive factor-5 (ERF5) were observed in WT and transgenic lines, suggesting an absence of drought conditions during initial stages of heat stress (data not shown).

Seedlings of overexpression lines grew well up to $200 \mathrm{mM}$ salt concentration (Fig. 5). WT seedlings showed retarded growth and chlorosis, when compared with the transgenic lines (Fig. 5A, B). Although growth of transgenic seedlings was retarded by $200 \mathrm{mM}$ $\mathrm{NaCl}$, the seedlings resumed their growth by $10 \mathrm{~d}$ after treatment when shifted gradually 
to $100 \mathrm{mM} \mathrm{NaCl}$ and then to stress free medium, i.e $1 / 2 \mathrm{MS}$ without $\mathrm{NaCl}$ (Fig. 5C). Seedlings grown in the presence of $100 \mathrm{mM}$ (Fig. S8) and $150 \mathrm{mM} \mathrm{NaCl}$ (Fig. 5D) showed differences in total chlorophyll content, thio-barbituric acid reactive substances (TBARS, an indicator of lipid peroxidation and membrane damage) and root length $20 \mathrm{~d}$ post treatment (Fig. 5F, G, I). WT seedlings did not survive and were bleached after $15 \mathrm{~d}$ on $150 \mathrm{mM} \mathrm{NaCl}$; seedlings of transgenic line \#19 showed some chlorosis and reduced growth when compared with high expression lines \#22 and \#25. Transgenic lines were able to survive and grow in $150 \mathrm{mM} \mathrm{NaCl}$; however, their growth was slow when compared with growth under the no-stress condition (Fig. 5D). Similar observations were made in the leaf disc assay (Fig. S6). Interestingly, this improved salt stress tolerance was found to be associated with reduction in accumulation of reactive oxygen species (ROS) (Fig. 5H, S7). These observations clearly suggest the involvement of AdDjSKI in maintaining membrane stability and redox balance inside the chloroplast, thereby aiding photosynthesis under stress.

$A d D j S K I$ transgenic seedlings not only performed better under heat and salt stress but also under drought and osmotic stress conditions created by polyethylene glycol (PEG-6000), (Fig. S8, S9A), sorbitol, mannitol (Fig. S9A) and $\mathrm{H}_{2} \mathrm{O}_{2}$ (Fig. S8). They developed longer roots (Fig. S9B) displaying the capacity to maintain root growth under water deficient conditions and also were able to retain $80-90 \%$ of water as evident from their relative water content (Fig. S9C). Our seedling assay observations in the various stress treatments suggest a role for AdDjSKI in maintaining protein homeostasis and reducing elevated ROS levels in chloroplasts under stress while ensuring proper functioning of the plant's photosynthetic machinery.

Biotic stress: Overexpression lines showed enhanced resistance against phytopathogenic fungi Phytophthora parasitica pv. nicotianae and Sclerotinia sclerotiorum

Resistance responses against fungal pathogens were compared in detached leaves of WT and transgenic plant lines \#19,\#22 and \#25. These AdDjSKI transgenic $\mathrm{T}_{2}$ tobacco plants exhibited enhanced resistance against the phytopathogenic fungus $P$. parasitica var. 
nicotianae, a causative agent of black shank disease, and S. sclerotiorum, a causative agent of stem rot (Fig. 6A, D). Interestingly, the resistance response of the different transgenic plant progenies in this assay corresponded well to the expression level of AdDjSKI. The progeny of the transgenic lines \#22 and \#25 with high AdDjSKI expression levels showed significantly enhanced resistance against $P$. parasitica, in the form of completely reduced lesion area, and the lesion area developed more slowly in line \#19 (Fig. 6A, B). Significant reduction in the amount of fungal DNA was observed in all three transgenic lines in comparison to wild type (Fig. 6C), confirming that the transgenic plants resisted the growth of the pathogen in their leaves in comparison to the WT.

Expression levels of PRIa, PR1b, PR1c, PR2-Glucanase and PR5-Osmotin were found to be significantly upregulated in RT-PCR analyses of their expression in the transgenic lines \#22 and \#25 when compared with \#19 and WT $24 \mathrm{hr}$ post infection with $P$. parasitica (Fig. 7). Though a significant upregulation of Harpin-induced gene (HIN1) was not observed in the transgenic plants, the cell death-related proteins Patatin-like Phospholipase 3 (PAT3) and hyper-sensitivity related gene (HSR203J) were upregulated in the transgenic plants, suggesting a positive influence of the constitutive expression of $A d D j S K I$ in modulating the expression of these host proteins upon pathogen treatment (Fig. 7). Significant upregulation observed in the expression of $P R$ genes 0 hpi (control) in transgenic leaves can be attributed to wounding, as the control condition in this experiment measured expression in uninoculated leaves $24 \mathrm{hr}$ after leaf detachment.

Similarly, the leaves of transgenic lines \#19, \#22 and \#25 showed enhanced resistance against the stem rot causal agent S. sclerotiorum, where leaves of WT plants showed chlorosis and rotting starting from the mid rib region (Fig. 6D, E). Also, a significant reduction in the amount of fungal DNA was observed in transgenic lines in comparison to wild type for all three transgenic lines, clearly showing the inhibited growth of the pathogen in the leaves (Fig. 6F).

\section{Discussion}


Our transcript and protein profiling studies in A.diogoi showed that its cellular machinery is well supplied with stress-combating proteins, which also include chaperones like DnaJ, HSP70 and SGT1 [1-3]. Upregulation at transcript levels is not always the same at protein levels; proteins can become non-functional when increased ROS levels damage their functional core. Moreover, it is very common to see stress-responsive proteins rendered nonfunctional by protein aggregation when overexpressed beyond a threshold level. With this in view, having multiple chaperones to assist in protein homeostasis seems to be as important as having stress-responsive genes. It was interesting to observe that overexpression of chloroplastic AdDjSKI enhanced abiotic stress tolerance in E. coli, although $E$. coli has no paralogues of this protein. In bacteria, folding and translocation of de-novo synthesized cytosolic proteins is assisted by three conserved molecular chaperones: trigger factor (TF), DnaK (HSP70) and GroEL (HSP60) [45]. However in plants, the interaction of DnaK with nascent peptide begins with binding of DnaJ protein to an unfolded peptide. DnaJ-assisted ATP hydrolysis by DnaK leads to its concomitant conformational changes driving the release of properly folded functionally active polypeptide [10].

Expression profiling of $A d D j S K I$ under different hormonal and chemical treatments in $A$. diogoi suggested its involvement in various abiotic and biotic stress-related molecular pathways. This transcriptional upregulation of $A d D j S K I$ under SA, MeJA, SNP, $\mathrm{H}_{2} \mathrm{O}_{2}$, $\mathrm{MV}$ and $\mathrm{NaCl}$ can be a result of generalized stress response. As a co-chaperone of HSP70 this J-protein is perhaps needed with the onset of stress for folding of stress responsive proteins to avoid protein aggregation and improper folding of proteins in response to elevated ROS levels. Interestingly, we recorded an upregulation of $A d D j S K I$ just 5 min after the initiation of heat stress. Previously, a DnaJ-like protein was also observed to be upregulated in a suppression subtractive hybridization ( $\mathrm{SSH}$ ) cDNA library of Vigna aconitifolia under an early heat stress of $5 \mathrm{~min}$ [46], suggesting that J-proteins are the first amongst several heat shock proteins to be induced under high temperature stress conditions. Moreover, the transgenic lines performed better under heat stress conditions associated with the transcriptional upregulation of antioxidant-related genes as well as of HSP70s. The localization of punctate AdDjSKI in chloroplasts, possibly in the 
membranes of thylakoid or stroma lamellae, suggests that it is involved in folding of proteins associated with photosynthesis. This would explain the enhanced tolerance of transgenic lines against the wide spectrum of stresses observed in the present study.

Chloroplast-targeted AdDjSKI protein overexpression potentiated tolerance to multiple stresses in Nicotiana tabacum var Samsun and had no detrimental effects on the growth of plants. Stress tolerance observed in overexpression lines seems to have resulted from transcriptional upregulation of $A P X, M n-S O D$, sucrose synthase, and Hsp70s under heat stress and $P R$ genes in response to phytopathogenic fungi such as Phytophthora parasitica pv nicotianae. The chloroplast can act as a sensor of intra- and extracellular stimuli and hence can integrate a multitude of intracellular signals and pathways in order to sustain homeostasis at both the cellular and organismal levels [47]. For example, biosynthesis of many plant hormones including auxin, gibberellins, abscisic acid, JA, and brassinosteroids as well as salicylic acid [48] occurs in the chloroplast. Thus chloroplasts are closely involved in the coordination of abiotic and biotic stress responses [49]. AdDjSKI seems to protect chloroplast proteins presumably by ensuring folding of ROS scavengers such as Mn-SOD and APX. We also see a reduction in ROS accumulation in stomata of overexpression lines \#22 and \#25 when compared with WT under $\mathrm{NaCl}$ treatment (Fig. S7). Moreover, we observed better growth of seedlings under $\mathrm{H}_{2} \mathrm{O}_{2}$ treatment (Fig. S8). High ROS accumulation in chloroplasts is detrimental and can disrupt the electron transport chain, hamper photosynthesis and also influence hormone biosynthesis as well as retrograde signaling by chloroplasts [50-54]. AdDjSKI can ensure proper functioning of the chloroplast by reducing its ROS level.

Previously, J-proteins have been reported to enhance disease resistance against phytopathogenic bacteria such as Ralstonia solanacearum [55], where the phenotype observed was associated with marked upregulation of PRla and PR2 [55]. This is the first report in which it was shown that transgenic plants overexpressing AdDjSKI having a single C-terminal 4Fe-4S cluster exhibited enhanced resistance against two phytopathogenic fungi viz. P. parasitica and S. sclerotiorum, in association with enhanced expression of genes for several PR proteins and cell-death associated proteins viz., PAT3 
and HSR203J. Normally, a fitness cost is observed in plants with enhanced expression of $P R$ and cell death associated genes [56]. It is therefore unusual to have a gene whose ectopic expression is associated with transcriptional upregulation of $P R$ genes, but does not have a fitness cost. This makes $A d D j S K I$ a good candidate for engineering enhanced abiotic and biotic stress resistance for agriculture. In the light of the new data presented here, it will be interesting to overexpress $A d D j S K I$ in crop plants such as tomato or peanut and assess their abiotic as well biotic stress tolerance levels.

\section{Conclusion}

In the present study we have isolated, cloned and characterized pathogen-induced AdDjSKI having an $\mathrm{N}$-terminal J-domain and a C-terminal ferredoxin domain. The expression profile suggests that the expression of $A d D j S K I$ is not influenced by a particular type of stress signal, but is ubiquitously expressed during stress irrespective of its type. Moreover, its upregulation under MeJA, salicyclic acid (SA) and ethephon treatment suggests the involvement of AdDjSKI in an interconnected signaling network. Ectopic expression of $A d D j S K I$ in E. coli and tobacco conferred tolerance to multiple stresses. Transgenic plants showed better growth under heat stress, salinity stress, osmotic stress and drought stress along with enhanced tolerance to the phytopathogenic fungi $P$. parasitica pv nicotianae and Sclerotinia sclerotiorum. We propose that chloroplastlocalized AdDjSKI maintains and protects the photosynthetic machinery under stress conditions by reducing otherwise elevated ROS levels, thereby ensuring retrograde signaling from chloroplasts as evident from transcriptional upregulation of stress-related genes.

\section{Disclosure}

The authors declare that the research was conducted in the absence of any commercial or financial relationships that could be construed as a potential conflict of interest.

\section{Author Contribution}

PBK designed the project, SR, PB, CR, acquired the data, where SR, PB and AS performed experiments related to heterologous expression in Nicotiana tabacum var 
Samsun and CR did experiments related to subcellular localization in Nicotiana benthamiana. PBK, WG and SR analyzed, interpreted the data and wrote the paper.

\section{Funding}

This work was supported by a Research Grant (BT/PR6853/PBD/16/627/2005) by the Department of Biotechnology, Government of India to one of the authors (PBK). SR acknowledges the Fellowship from the 'Inspire Program'-DST- Government of India and Foreign Fulbright Scholarship Board (FFSB).

\section{Acknowledgments}

Authors acknowledge Dr. Dilip Kumar, for his suggestions and help since commencement of this study. Dr. Christopher M Garner for his help in taking confocal images. Dr. Jianbin $\mathrm{Su}$ and Sharon Pike for editing the manuscript.

\section{Literature Cited}

[1] K.R. Kumar, P.B. Kirti, Differential gene expression in Arachis diogoi upon interaction with peanut late leaf spot pathogen, Phaeoisariopsis personata and characterization of a pathogen induced cyclophilin, Plant Mol Biol, 75 (2011) 497-513.

[2] A. Kumar, W. Bimolata, M. Kannan, P.B. Kirti, I.A. Qureshi, I.A. Ghazi, Comparative proteomics reveals differential induction of both biotic and abiotic stress response associated proteins in rice during Xanthomonas oryzae pv. oryzae infection, Funct Integr Genomics, 15 (2015) 425-437.

[3] D. Kumar, P.B. Kirti, Transcriptomic and proteomic analyses of resistant host responses in Arachis diogoi challenged with late leaf spot pathogen, Phaeoisariopsis personata, PLoS One, 10 (2015).

[4] D. Kumar, P.B. Kirti, Pathogen-induced SGT1 of Arachis diogoi induces cell death and enhanced disease resistance in tobacco and peanut, Plant Biotechnol J, 13 (2015) 73-84.

[5] D. Kumar, S. Rampuria, N.K. Singh, P. Shukla, P.B. Kirti, Characterization of a vacuolar processing enzyme expressed in Arachis diogoi in resistance responses against late leaf spot pathogen, Phaeoisariopsis personata, Plant Mol Biol, 88 (2015) 177-191. [6] K.R. Kumar, P.B. Kirti, Novel role for a serine/arginine-rich splicing factor, AdRSZ21 in plant defense and HR-like cell death, Plant Mol Biol, 80 (2012) 461-476.

[7] A. Sharma, D. Kumar, S. Kumar, S. Rampuria, A.R. Reddy, P.B. Kirti, Ectopic expression of an atypical hydrophobic group 5 LEA protein from wild peanut, Arachis diogoi confers abiotic stress tolerance in tobacco, PLoS One, 11 (2016) e0150609.

[8] M. Pajares, N. Jiménez-Moreno, I.H.K. Dias, B. Debelec, M. Vucetic, K.E. Fladmark, H. Basaga, S. Ribaric, I. Milisav, A. Cuadrado, Redox control of protein degradation, Redox Biology, 6 (2015) 409-420.

[9] C.-J. Park, Y.-S. Seo, Heat Shock Proteins: A review of the molecular chaperones for plant immunity, The Plant Pathology Journal, 31 (2015) 323-333. 
[10] J.A. Miernyk, Protein folding in the plant cell, Plant Physiology, 121 (1999) 695-703. [11] Joint Genome Institute[http://www.jgi.doe.gov].

[12] F. Hennessy, M.E. Cheetham, H.W. Dirr, G.L. Blatch, Analysis of the levels of conservation of the $\mathrm{J}$ domain among the various types of DnaJ-like proteins, Cell Stress Chaperones, 5 (2000) 347-358.

[13] D.A. Parsell, S. Lindquist, The function of heat-shock proteins in stress tolerance: degradation and reactivation of damaged proteins, Annu Rev Genet, 27 (1993) 437-496.

[14] J.A. Miernyk, The J-domian proteins of Arabidopsis thaliana: an unexpectedly large and diverse family of chaperones, Cell Stress Chaperon, 6 (2001).

[15] J. Jelenska, J.A. van Hal, J.T. Greenberg, Pseudomonas syringae hijacks plant stress chaperone machinery for virulence, Proceedings of the National Academy of Sciences of the United States of America, 107 (2010) 13177-13182.

[16] J.Z. Liu, S.A. Whitham, Overexpression of a soybean nuclear localized type-III DnaJ domain-containing HSP40 reveals its roles in cell death and disease resistance, Plant J, 74 (2013) $110-121$.

[17] D. Bekh-Ochir, S. Shimada, A. Yamagami, S. Kanda, K. Ogawa, M. Nakazawa, M. Matsui, M. Sakuta, H. Osada, T. Asami, T. Nakano, A novel mitochondrial DnaJ/Hsp40 family protein BIL2 promotes plant growth and resistance against environmental stress in brassinosteroid signaling, Planta, 237 (2013) 1509-1525.

[18] G. Wang, G. Cai, F. Kong, Y. Deng, N. Ma, Q. Meng, Overexpression of tomato chloroplast-targeted DnaJ protein enhances tolerance to drought stress and resistance to Pseudomonas solanacearum in transgenic tobacco, Plant Physiology and Biochemistry, 82 (2014) 95-104.

[19] K.M. Chen, M. Holmstrom, W. Raksajit, M. Suorsa, M. Piippo, E.M. Aro, Small chloroplast-targeted DnaJ proteins are involved in optimization of photosynthetic reactions in Arabidopsis thaliana, BMC Plant Biol, 10 (2010) 1471-2229.

[20] G. Wang, F. Kong, S. Zhang, X. Meng, Y. Wang, Q. Meng, A tomato chloroplasttargeted DnaJ protein protects Rubisco activity under heat stress, J Exp Bot, 66 (2015) 3027-3040.

[21] K.-M. Chen, M. Holmström, W. Raksajit, M. Suorsa, M. Piippo, E.-M. Aro, Small chloroplast-targeted DnaJ proteins are involved in optimization of photosynthetic reactions in Arabidopsis thaliana, BMC Plant Biology, 10 (2010) 1-15.

[22] K. Brzoska, S. Meczynska, M. Kruszewski, Iron-sulfur cluster proteins: electron transfer and beyond, Acta Biochim Pol, 53 (2006) 685-691.

[23] Karolin V. Dorn, F. Willmund, C. Schwarz, C. Henselmann, T. Pohl, B. Hess, D. Veyel, B. Usadel, T. Friedrich, J. Nickelsen, M. Schroda, Chloroplast DnaJ-like proteins 3 and 4 (CDJ3/4) from Chlamydomonas reinhardtii contain redox-active Fe-S clusters and interact with stromal HSP70B, Biochemical Journal, 427 (2010) 205-215.

[24] K. Tamura, J. Dudley, M. Nei, S. Kumar, MEGA4: Molecular Evolutionary Genetics Analysis (MEGA) software version 4.0, Mol Biol Evol, 24 (2007) 1596-1599.

[25] E. de Castro, C.J.A. Sigrist, A. Gattiker, V. Bulliard, P.S. Langendijk-Genevaux, E. Gasteiger, A. Bairoch, N. Hulo, ScanProsite: detection of PROSITE signature matches and ProRule-associated functional and structural residues in proteins, Nucleic Acids Research, 34 (2006) W362-W365.

[26] S. Chang, J. Puryear, J. Cairney, A simple and efficient method for isolating RNA from pine trees, Plant Mol Biol Rep, 11 (1993) 113-116. 
[27] D. Kumar, S. Rampuria, N.K. Singh, P.B. Kirti, A novel zinc $\square$ binding alcohol dehydrogenase 2 from Arachis diogoi, expressed in resistance responses against late leaf spot pathogen, induces cell death when transexpressed in tobacco, FEBS Open Bio, 6 (2016) 200-210.

[28] K.J. Livak, T.D. Schmittgen, Analysis of relative gene expression data using real-time quantitative PCR and the 2- $\Delta \Delta \mathrm{CT}$ Method, Methods, 25 (2001) 402-408.

[29] T.E. Gookin, S.M. Assmann, Significant reduction of BiFC non-specific assembly facilitates in planta assessment of heterotrimeric G-protein interactors, Plant J, 80 (2014) 553-567.

[30] Y. Yang, R. Li, M. Qi, In vivo analysis of plant promoters and transcription factors by agroinfiltration of tobacco leaves, Plant J, 22 (2000) 543-551.

[31] R. Töpfer, V. Matzeit, B. Gronenborn, J. Schell, H.H. Steinbiss, A set of plant expression vectors for transcriptional and translational fusions, Nucleic Acids Research, 15 (1987) 5890 .

[32] P. Hajdukiewicz, Z. Svab, P. Maliga, The small, versatilepPZP family of Agrobacterium binary vectors for plant transformation, Plant Molecular Biology, 25 (1994) 989-994.

[33] M. Holsters, D. de Waele, A. Depicker, E. Messens, M. van Montagu, J. Schell, Transfection and transformation of Agrobacterium tumefaciens, Mol Gen Genet, 163 (1978) 181-187.

[34] R.B. Horsch, J.E. Fry, N.L. Hoffman, D. Eichholtz, S.G. Rogers, R.T. Fraley, A simple and general method for transferring genes into plants, Science, 227 (1985) 1229-1231.

[35] J.J. Doyle, J.L. Doyle, Isolation of plant DNA from fresh tissues, Focus, 12 (1990) 13 15.

[36] K. Sanmiya, K. Suzuki, Y. Egawa, M. Shono, Mitochondrial small heat-shock protein enhances thermotolerance in tobacco plants, FEBS Letters, 557 (2004) 265-268.

[37] J.D. Hiscox, G.F. Israelstam, A method for the extraction of chlorophyll from leaf tissue without maceration, Canadian Journal of Botany, 57 (1979) 1332-1334.

[38] R.L. Heath, L. Packer, Photoperoxidation in isolated chlroplasts .I. Kinetics and stoichiometry of fatty acid peroxidation, Archives of Biochemistry and Biophysics, 125 (1968) 189-\&.

[39] D. Konopka-Postupolska, G. Clark, G. Goch, J. Debski, K. Floras, A. Cantero, B. Fijolek, S. Roux, J. Hennig, The role of annexin 1 in drought stress in Arabidopsis, Plant Physiology, 150 (2009) 1394-1410.

[40] E.C. Tedford, T.L. Miller, M.T. Nielsen, A detached-leaves techniques for detecting Phytophthora parasitica var. nicotianae in tobacco, Plant Disease, 74 (1990) 313-316.

[41] S.B. Lee, J.W. Taylor, 34 - Isolation of DNA from fungal mycelia and single spores, in: M.A. Innis, D.H. Gelfand, J.J.S.J. White (Eds.) PCR Protocols, Academic Press, San Diego, 1990, pp. 282-287.

[42] H. Bannai, Y. Tamada, O. Maruyama, K. Nakai, S. Miyano, Extensive feature detection of N-terminal protein sorting signals, Bioinformatics, 18 (2002) 298-305.

[43] I. Small, N. Peeters, F. Legeai, C. Lurin, Predotar: A tool for rapidly screening proteomes for N-terminal targeting sequences, Proteomics, 4 (2004) 1581-1590.

[44] O. Emanuelsson, H. Nielsen, S. Brunak, G. von Heijne, Predicting subcellular localization of proteins based on their N-terminal amino acid sequence, J Mol Biol, 300 (2000) 1005-1016. 
[45] M.P. Castanie-Cornet, N. Bruel, P. Genevaux, Chaperone networking facilitates protein targeting to the bacterial cytoplasmic membrane, Biochim Biophys Acta, 8 (2014) 21.

[46] S. Rampuria, U. Joshi, P. Palit, A.A. Deokar, R.R. Meghwal, T. Mohapatra, R. Srinivasan, K.V. Bhatt, R. Sharma, Construction and analysis of an SSH cDNA library of early heat-induced genes of Vigna aconitifolia variety RMO-40, Genome, 55 (2012) 783796.

[47] N. Driedonks, J. Xu, J.L. Peters, S. Park, I. Rieu, Multi-level interactions between heat shock factors, heat shock proteins, and the redox system regulate acclimation to heat, Frontiers in Plant Science, 6 (2015) 999.

[48] C. Fragnière, M. Serrano, E. Abou-Mansour, J.-P. Métraux, F. L'Haridon, Salicylic acid and its location in response to biotic and abiotic stress, FEBS Letters, 585 (2011) 18471852.

[49] G. Schmitz, T. Reinhold, C. Göbel, I. Feussner, H.E. Neuhaus, U. Conrath, Limitation of nocturnal ATP import into chloroplasts seems to affect hormonal crosstalk, prime defense, and enhance disease resistance in Arabidopsis thaliana, Molecular Plant-Microbe Interactions, 23 (2010) 1584-1591.

[50] B.C. Tripathy, R. Oelmüller, Reactive oxygen species generation and signaling in plants, Plant Signaling \& Behavior, 7 (2012) 1621-1633.

[51] T. Roach, A.K. Krieger-Liszkay, Regulation of photosynthetic electron transport and photoinhibition, Current Protein \& Peptide Science, 15 (2014) 351-362.

[52] S. Ehonen, D. Yarmolinsky, H. Kollist, J. Kangasjarvi, Reactive oxygen species, photosynthesis and environment in the regulation of stomata, Antioxid Redox Signal, 14 (2017).

[53] P. Sharma, A.B. Jha, R.S. Dubey, M. Pessarakli, Reactive oxygen species, oxidative damage, and antioxidative defense mechanism in plants under stressful conditions, Journal of Botany, 2012 (2012) 26.

[54] T. Maruta, M. Noshi, A. Tanouchi, M. Tamoi, Y. Yabuta, K. Yoshimura, T. Ishikawa, S. Shigeoka, $\mathrm{H}_{2} \mathrm{O}_{2}$-triggered retrograde signaling from chloroplasts to nucleus plays specific role in response to stress, J Biol Chem, 287 (2012) 11717-11729.

[55] G. Wang, G. Cai, F. Kong, Y. Deng, N. Ma, Q. Meng, Overexpression of tomato chloroplast-targeted DnaJ protein enhances tolerance to drought stress and resistance to Pseudomonas solanacearum in transgenic tobacco, Plant Physiol Biochem, 82 (2014) 95104.

[56] Y. Ning, W. Liu, G.-L. Wang, Balancing immunity and yield in crop plants, Trends in Plant Science, (2017).

[57] B. Kroczynska, R. Zhou, C. Wood, J.A. Miernyk, AtJ1, a mitochondrial homologue of the Escherichia coli DnaJ protein, Plant Mol Biol, 31 (1996) 619-629.

[58] W. Zhou, T. Zhou, M.X. Li, C.L. Zhao, N. Jia, X.X. Wang, Y.Z. Sun, G.L. Li, M. Xu, R.G. Zhou, B. Li, The Arabidopsis J-protein AtDjB1 facilitates thermotolerance by protecting cells against heat-induced oxidative damage, New Phytol, 194 (2012) 364-378. [59] C. Liu, F. Willmund, J.R. Golecki, S. Cacae, B. Heâ, C. Markert, M. Schroda, The chloroplast HSP70B-CDJ2-CGE1 chaperones catalyse assembly and disassembly of VIPP1 oligomers in Chlamydomonas, Plant J, 50 (2007).

[60] F. Willmund, K.V. Dorn, M. Schulz-Raffelt, M. Schroda, The chloroplast DnaJ homolog CDJ1 of Chlamydomonas reinhardtii is part of a multichaperone complex 
containing HSP70B, CGE1, and HSP90C, Plant Physiol, 148 (2008) 2070-2082.

[61] N. Futamura, N. Ishiiminami, N. Hayashida, K. Shinohara, Expression of DnaJ homologs and Hsp70 in the Japanese willow (Salix gilgiana Seemen), Plant Cell Physiol, 40 (1999) 524-531.

[62] J. Diefenbach, H. Kindl, The membrane-bound DnaJ protein located at the cytosolic site of glyoxysomes specifically binds the cytosolic isoform 1 of Hsp70 but not other Hsp70 species, Eur J Biochem, 267 (2000) 746-754.

[63] K.M. Chen, M. Piippo, M. Holmstrom, M. Nurmi, E. Pakula, M. Suorsa, E.M. Aro, A chloroplast-targeted DnaJ protein AtJ8 is negatively regulated by light and has rapid turnover in darkness, J Plant Physiol, 168 (2011) 1780-1783.

[64] S.M. Swarbreck, E.A. Lindquist, D.D. Ackerly, G.L. Andersen, Analysis of leaf and root transcriptomes of soil-grown Avena barbata plants, Plant Cell Physiol, 52 (2011) 317332.

[65] J.J. Bessoule, Occurrence and sequence of a DnaJ protein in plant (Allium porrum) epidermal cells, FEBS Lett, 323 (1993) 51-54.

[66] X. Zhu, S. Liang, J. Yin, C. Yuan, J. Wang, W. Li, M. He, W. Chen, B. Ma, Y. Wang, P. Qin, S. Li, X. Chen, The DnaJ OsDjA7/8 is essential for chloroplast development in rice (Oryza sativa), Gene, 574 (2015) 11-19.

[67] Z. Zhichang, Z. Wanrong, Y. Jinping, Z. Jianjun, L.Z.L. Xufeng, Y. Yang, Overexpression of Arabidopsis DnaJ (Hsp40) contributes to NaCl-stress tolerance, African Journal of Biotechnology, 9 (2010) 972-978.

\section{Figure Legends}

Table 1 List of the characterized DnaJ proteins in various systems.

Figure 1 Sequence analysis and subcellular localization of AdDjSKI. A. Cloning of AdDjSKI from Arachis diogoi. Representative image of 5' and 3' RACE PCR products for isolating full-length cDNA of $A d D j S K I$. B. Open reading frame of $A d D j S K I$. C. Phylogenetic analysis of DnaJ proteins. The analysis using a tree constructed by neighborjoining algorithms of MEGA 4.0 software after full-length protein sequence alignment using the ClustalW program resulted in classification of AdDjSKI as a type III J protein. Bootstrapping was performed to obtain support values for each branch and ExPASy's Prosite was used to determine conserved domains (a-c) which are indicated as follows: a, DnaJ domain; b, 4Fe-4S domain; c, Zn finger domain. D. Subcellular localization of Cterminally mVenus-tagged AdDjSKI to chloroplast. The YFP channel shows mVenustagged AdDjSKI, and the RFP channel free RFP in the cell cytoplasm and nucleus. 
Figure 2 Heterologous expression of $A d D j S K I$ in E. coli strain BL21. A. Spot assay showing better growth of recombinant BL21/AdDjSKI under various stress conditions up to $10^{5}$-fold dilutions when compared with BL21/pET32a. B-C. Growth kinetics of BL21/pET32a and BL21/AdDjSKI under abiotic stress conditions. At OD600nm=0.1, IPTG $(1 \mathrm{mM})$ was added to all the cultures. Bacterial cells were cultivated in LB medium supplemented with $400 \mathrm{mM}, 500 \mathrm{mM} \mathrm{NaCl}$ (B), pH 5, pH 7 (C), and $500 \mathrm{mM}, 700 \mathrm{mM}$ Sorbitol (D) for comparison, the same strains were grown in LB medium. Data are mean and standard deviation of three independent experiments.

Figure 3 RT-qPCR analysis of $A d D j S K I$ in response to various stress conditions in A.diogoi. RT-qPCR was performed using total cDNA isolated from samples collected at different time points following treatments with salicylic acid (SA), methyl jasmonate (MeJA), abscisic acid (ABA), ethephone, sodium nitroprusside (SNP), sorbitol, hydrogen peroxide $\left(\mathrm{H}_{2} \mathrm{O}_{2}\right)$, sodium chloride $(\mathrm{NaCl})$, polyethylene glycol MW 6000 (PEG MW 6000), methyl viologen (MV) and heat stress. For RT-qPCR analysis, primers were designed from the $3^{\prime}$ UTR of $A d D j S K I$. Asterisks indicate significantly increased accumulation relative to the mock sample $(* P<0.05, * * P<0.01, * * * P<0.001)$ as determined by one-way ANOVA. The primer sequences used in the study were given in Table S1.

Figure 4 Effect of heat stress on $A d D j S K I$ transgenic plants. A. Growth and condition of plants before heat stress. B. Phenotypic differences observed between WT and $A d D j S K I$ transgenic plants after $3 \mathrm{~h}$ of heat stress at $45^{\circ} \mathrm{C}$; WT was completely wilted. C. Phenotypic difference observed between WT and transgenic plants one week after heat stress treatment; transgenic lines $L-19, L-22, L-25$ resumed normal growth while WT became bleached and was not able to recover from heat injuries. D. Quantitative RT-PCR analysis of stressrelated genes was performed using total RNA from leaf samples collected 30 min post heat stress at $42{ }^{\circ} \mathrm{C}$. Relative expression was calculated by comparative $\Delta \Delta \mathrm{C}_{\mathrm{T}}$ method using actin as internal standard. Asterisks indicate upregulated expression relative to control samples as determined by one-way ANOVA $(* P<0.05, * * P<0.01, * * P<0.001)$. The primer sequences used in the study were given in Table S1. 
Figure 5 Effect of salinity stress on seedlings of $A d D j S K I$ transgenic plants. A. WT and transgenic seedling growth on $1 / 2$ MS medium. B. Seedling morphology $10 \mathrm{~d}$ post treatment with $1 / 2$ MS medium supplemented with $200 \mathrm{mM} \mathrm{NaCl}$, showing bleaching resulting from salt stress. C. Recovery of seedlings $10 \mathrm{~d}$ after $200 \mathrm{mM} \mathrm{NaCl}$ treatment. Seedlings of WT and transgenic lines were gradually shifted to $1 / 2 \mathrm{MS}$ medium; only seedlings of transgenic lines resumed normal growth. D. Individual seedling morphology after 20 days growth on $150 \mathrm{mM} \mathrm{NaCl}$, depicting differences in root length. E. Graphical representation of percentage of seedlings recovered 10 days post treatment with $200 \mathrm{mM} \mathrm{NaCl}$. F. Chlorophyll content ( $\mu \mathrm{g} \mathrm{mg}^{-1} \mathrm{FW}$ ) in seedlings grown on $100 \mathrm{mM}, 150 \mathrm{mM}$ and $200 \mathrm{mM}$ $\mathrm{NaCl}$. G. Lipid peroxidation expressed as TBARS content ( $\left.\mu \mathrm{mol} \mathrm{g}^{-1} \mathrm{FW}\right)$ in seedlings grown on different concentrations of $\mathrm{NaCl}$. H. Quantification of ROS production in stomata $(\mathrm{n}=150)$ after $\mathrm{H}_{2}$ DCFDA staining using ImageJ software. I. Graphic representation of root lengths of $\mathrm{NaCl}$-treated seedlings after 20 days growth on $100 \mathrm{mM}$ and $150 \mathrm{mM} \mathrm{NaCl}$, respectively. 11 seedlings constitute one biological sample for above performed assay. Data are plotted from 3 such experimental repeats with statistical analysis of variance (one-way ANOVA) $(* P<0.05, * * P<0.01, * * * P<0.001)$.

Figure 6 Detached leaf assay showing enhanced resistance of transgenic AdDjSKI overexpressing plants to infection with $P$. parasitica var. nicotianae and Sclerotinia sclerotiorum. A. T2 transgenic plants L-19 (low expression) and L-22 and L-25 (high expression) lines exhibited enhanced resistance to infection with $P$. parasitica var. nicotianae compared to WT plants 5 days post inoculation (dpi). B. Line diagram represents progression of symptoms that are expressed as area $\left(\mathrm{cm}^{2}\right)$ at 2-5 dpi. C. Quantification of pathogen DNA in infected tissues of tobacco inoculated with $P$. parasitica pv. nicotianae at 5 dpi. D. $T_{2}$ transgenic plants $L-19$ (low expression) and $L-22$ and $L-25$ (high expression) lines exhibited enhanced resistance to infection with $S$. sclerotiorum compared to WT plants 5 dpi. E. Bar diagram represents symptoms that are expressed as area $\left(\mathrm{cm}^{2}\right)$ of the diseased lesions area 7 dpi. F. Quantification of pathogen DNA in infected tissues of tobacco inoculated with $S$. sclerotiorum at 7 dpi. Data are plotted from 3 experimental repeats, and 
asterisks indicate statistically significant differences in gene expression levels relative to control samples as determined by one-way ANOVA $(* * P<0.01, * * * P<0.001)$.

Figure 7 Relative expression levels of $P R$ genes in WT and transgenic $L-19, L-22$ and $L$ 25, 24 hpi with P. parasitica pv nicotianae, where the control condition (C) is an untreated leaf $24 \mathrm{~h}$ after detachment. Data are plotted from 3 experimental repeats, and asterisks indicate significantly upregulated expression relative to control samples for each line $\left({ }^{*} P\right.$ $\left.<0.05 ; * * P 0.01 ;{ }^{* * *} P<0.001\right)$ as determined by one-way ANOVA. The primer sequences used in the study are listed in Table S1

Figure 1 
A

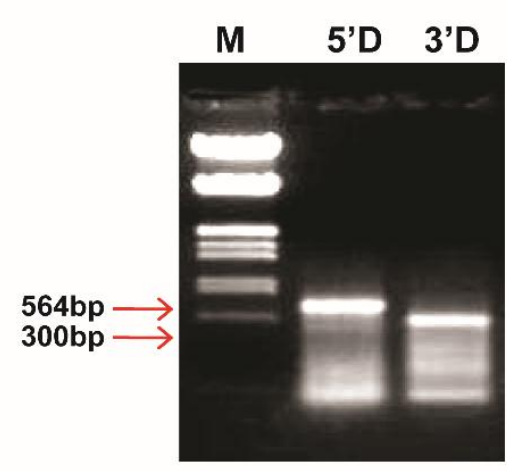

B

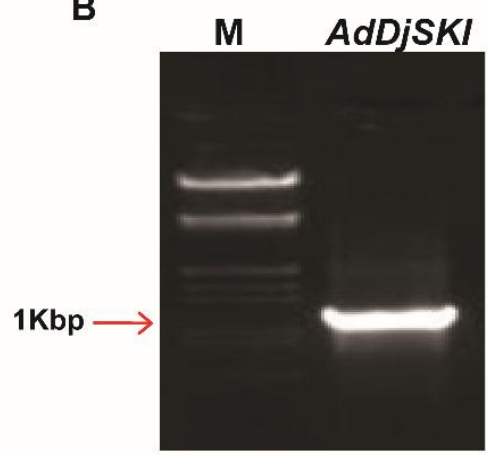

C

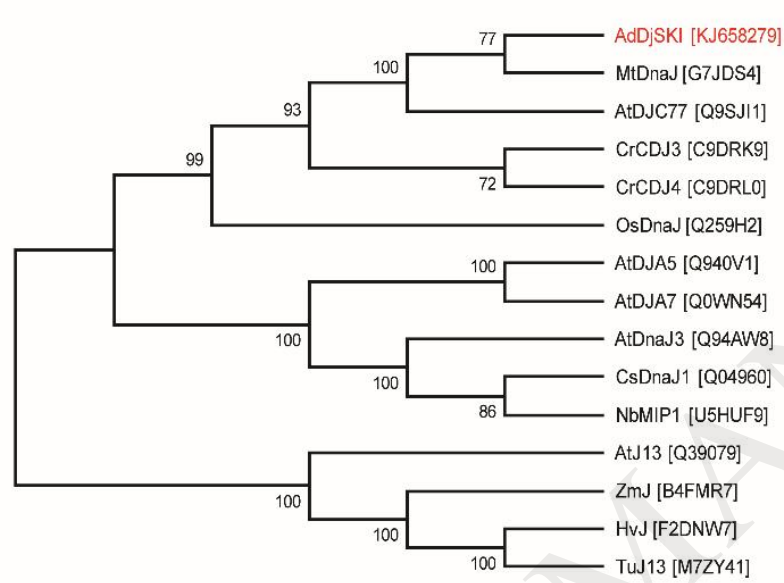

D

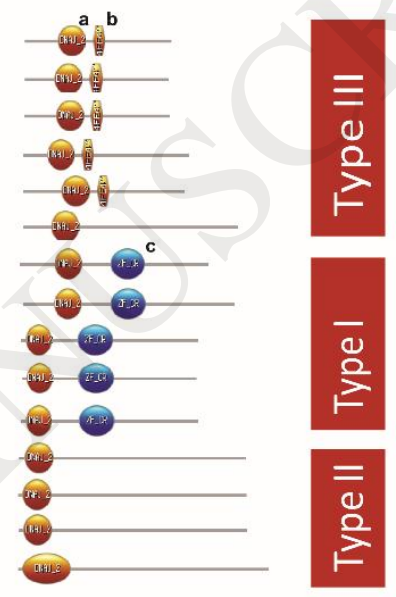

YFP Fluroscence

Chlorophyll Fluroscence

RFP Fluroscence

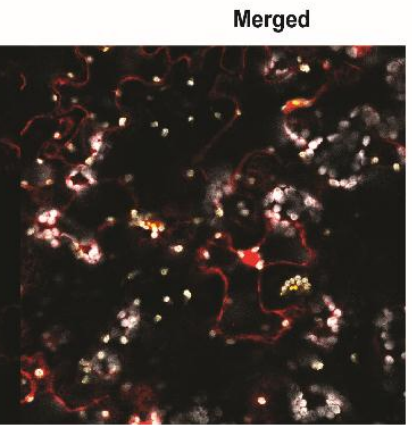

Figure 2 
A
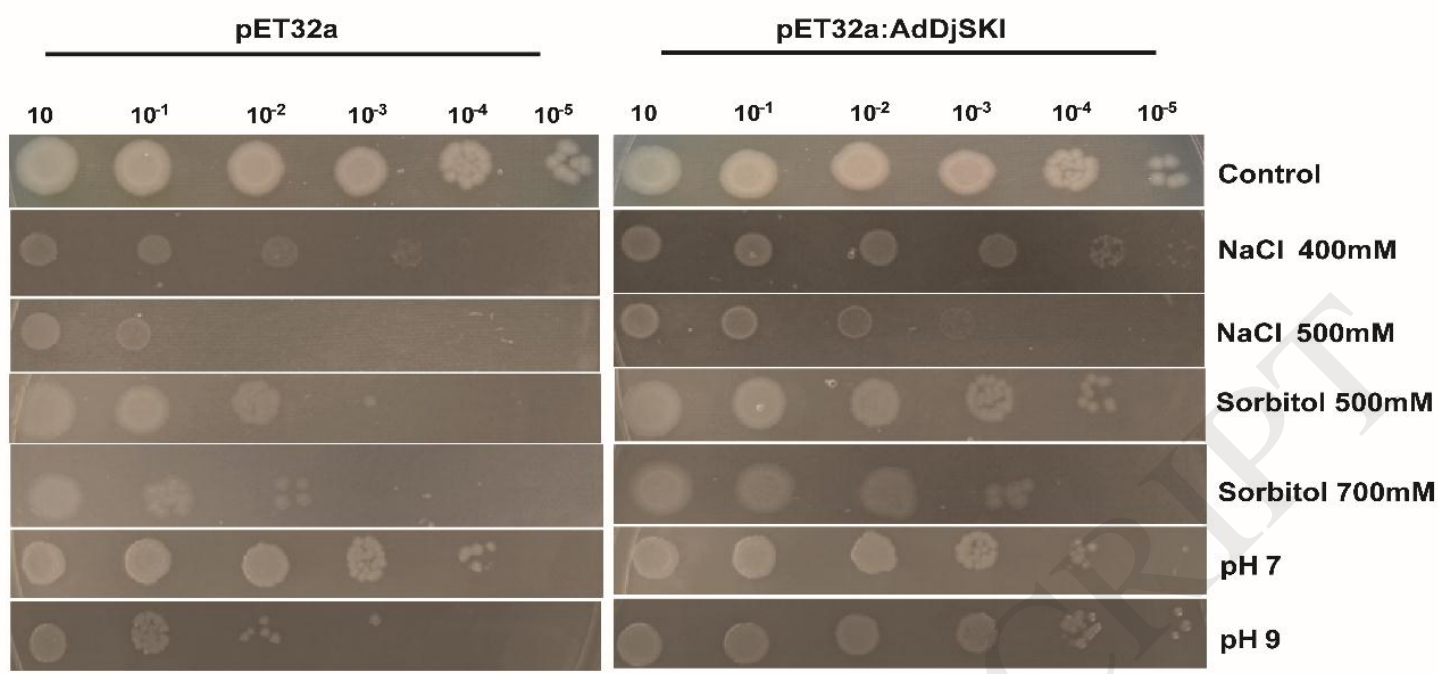

B

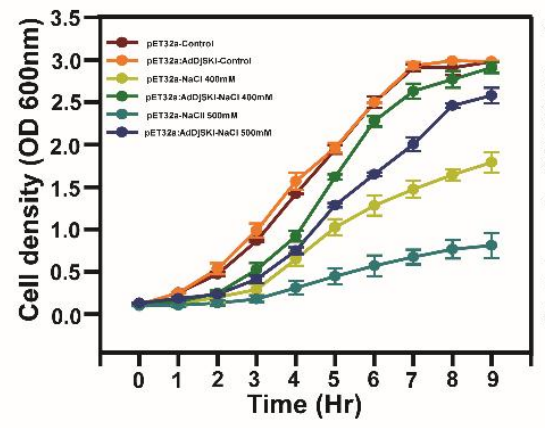

C

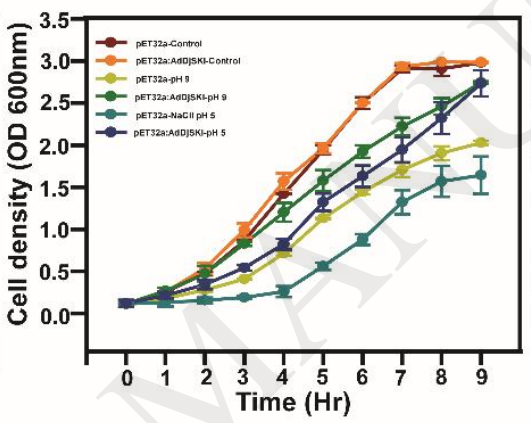

\section{D}

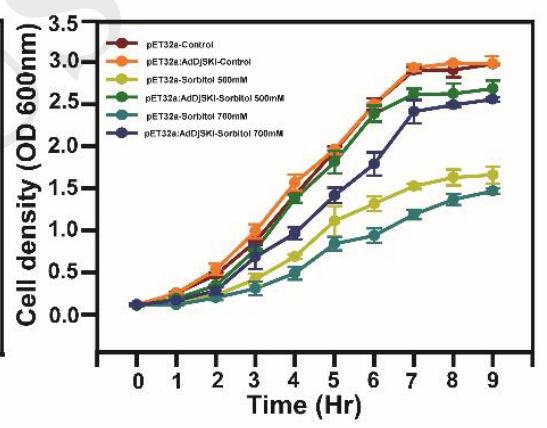

Figure 3 

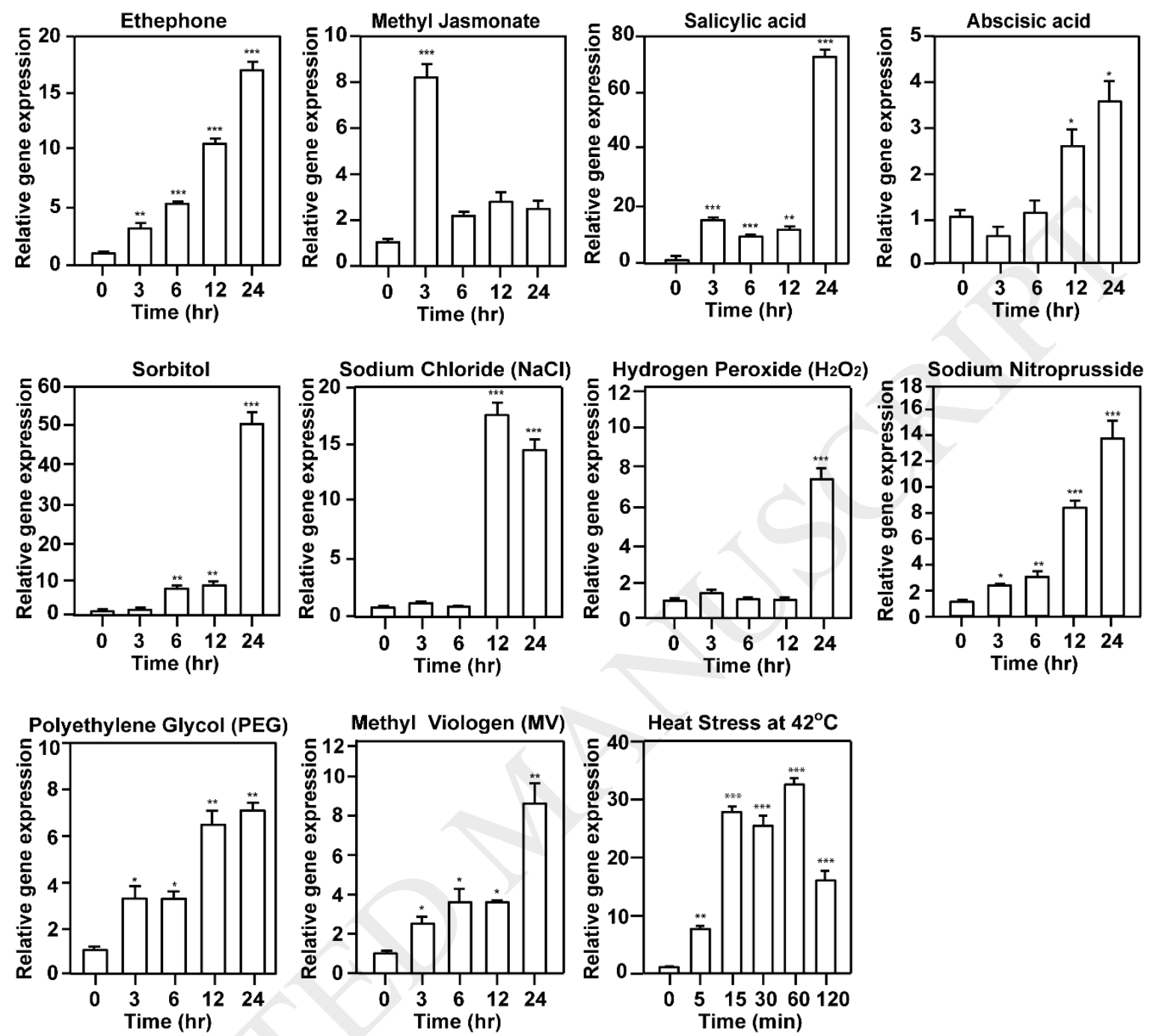

Figure 4 

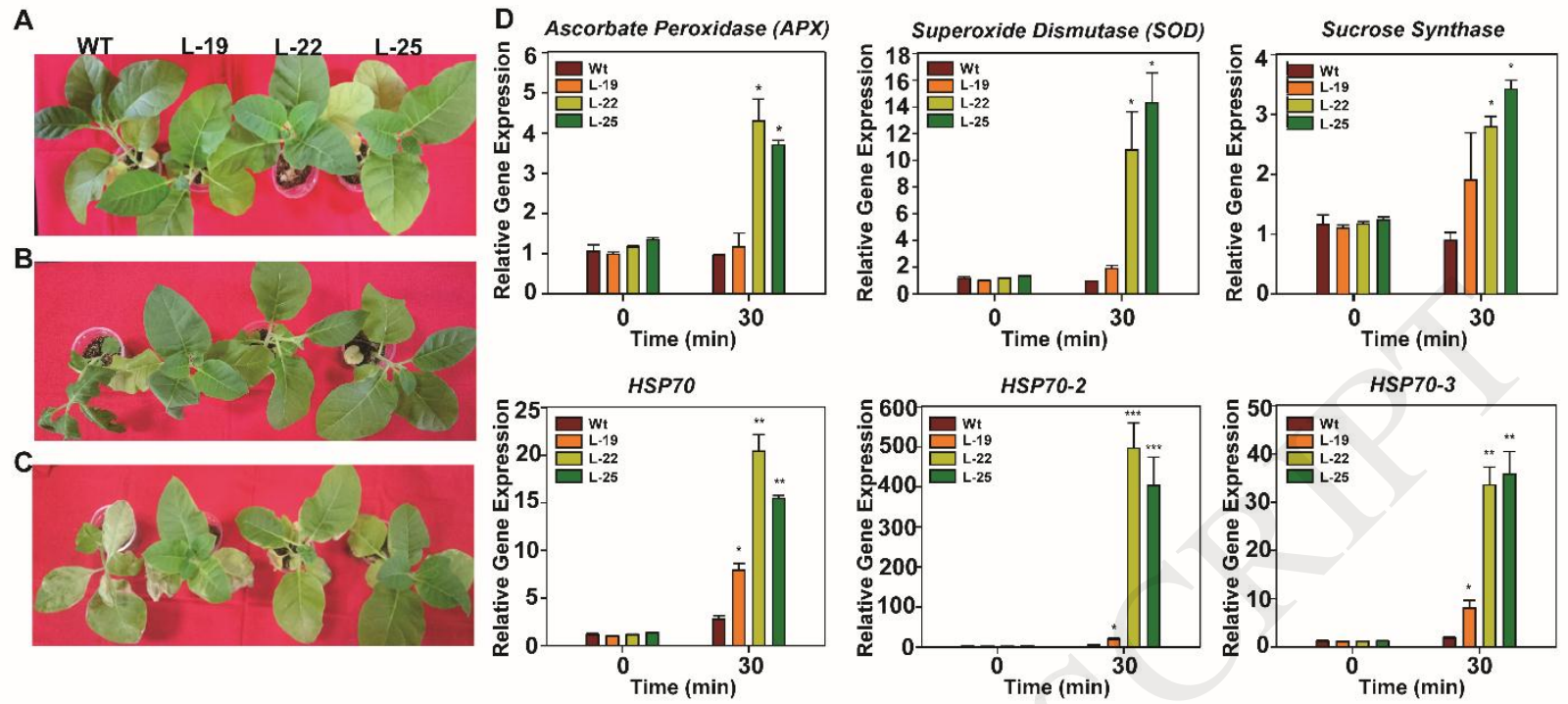

Figure 5

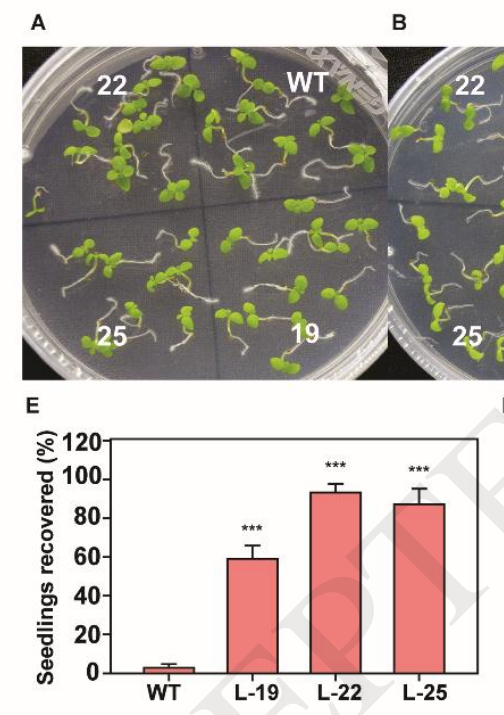

c

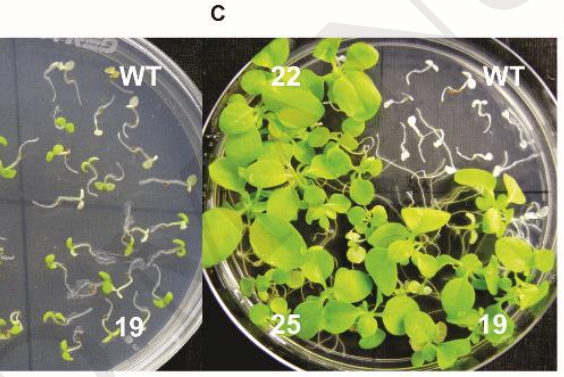

$F$
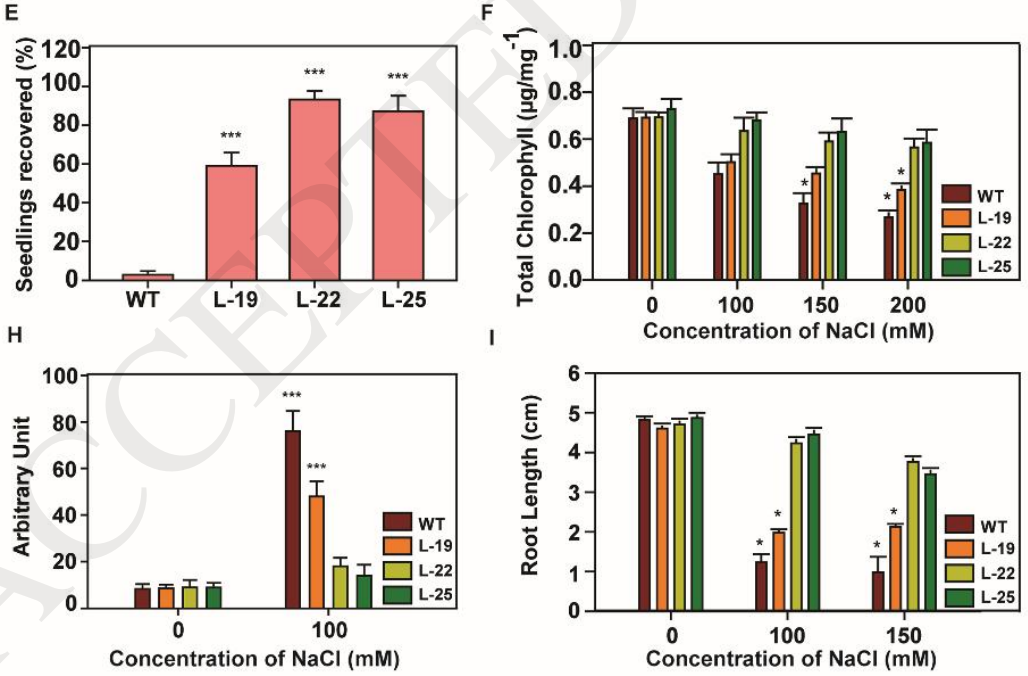

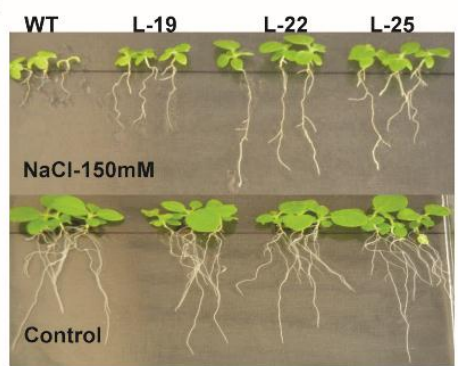

G

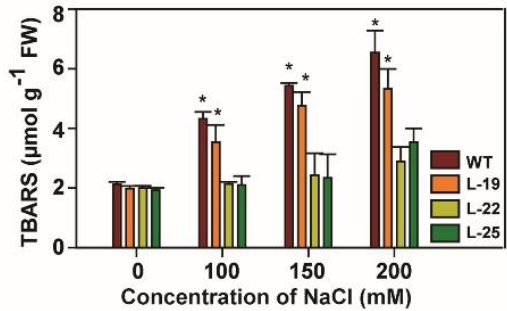

Figure 6 

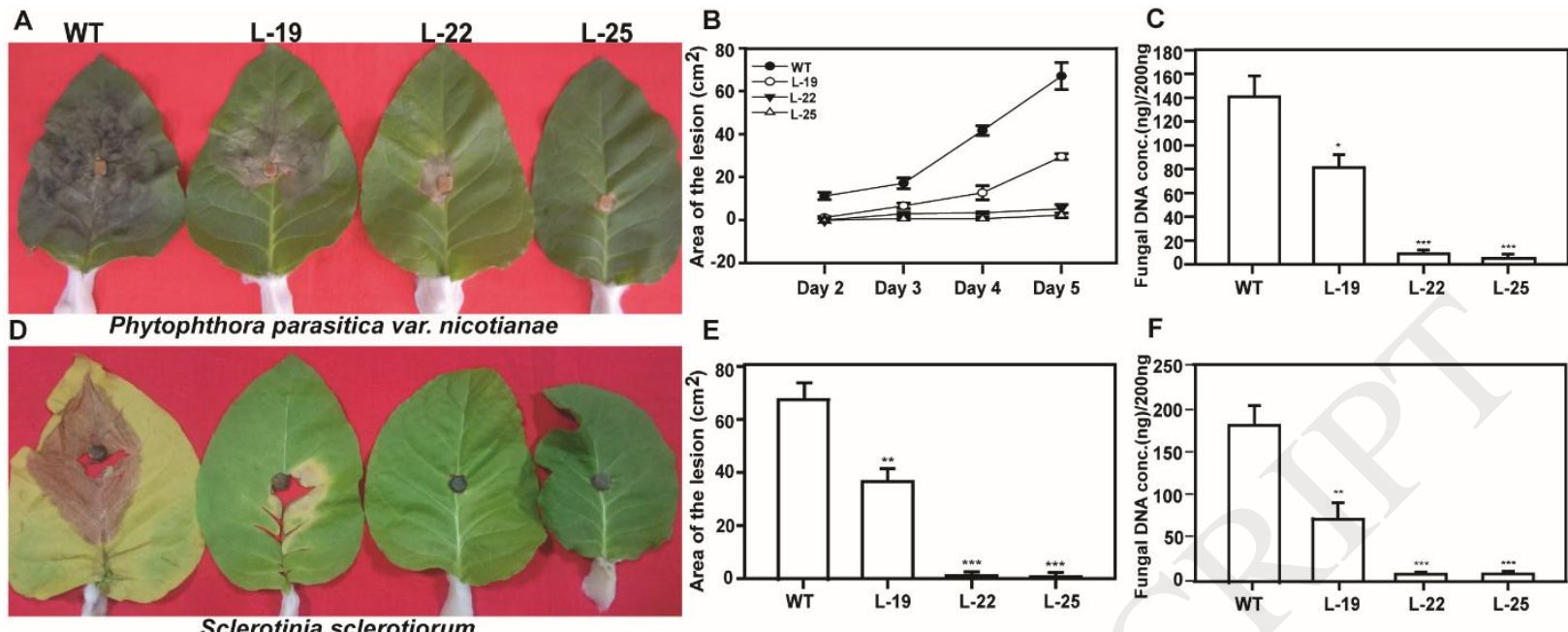

\section{Sclerotinia sclerotiorum}

Figure 7
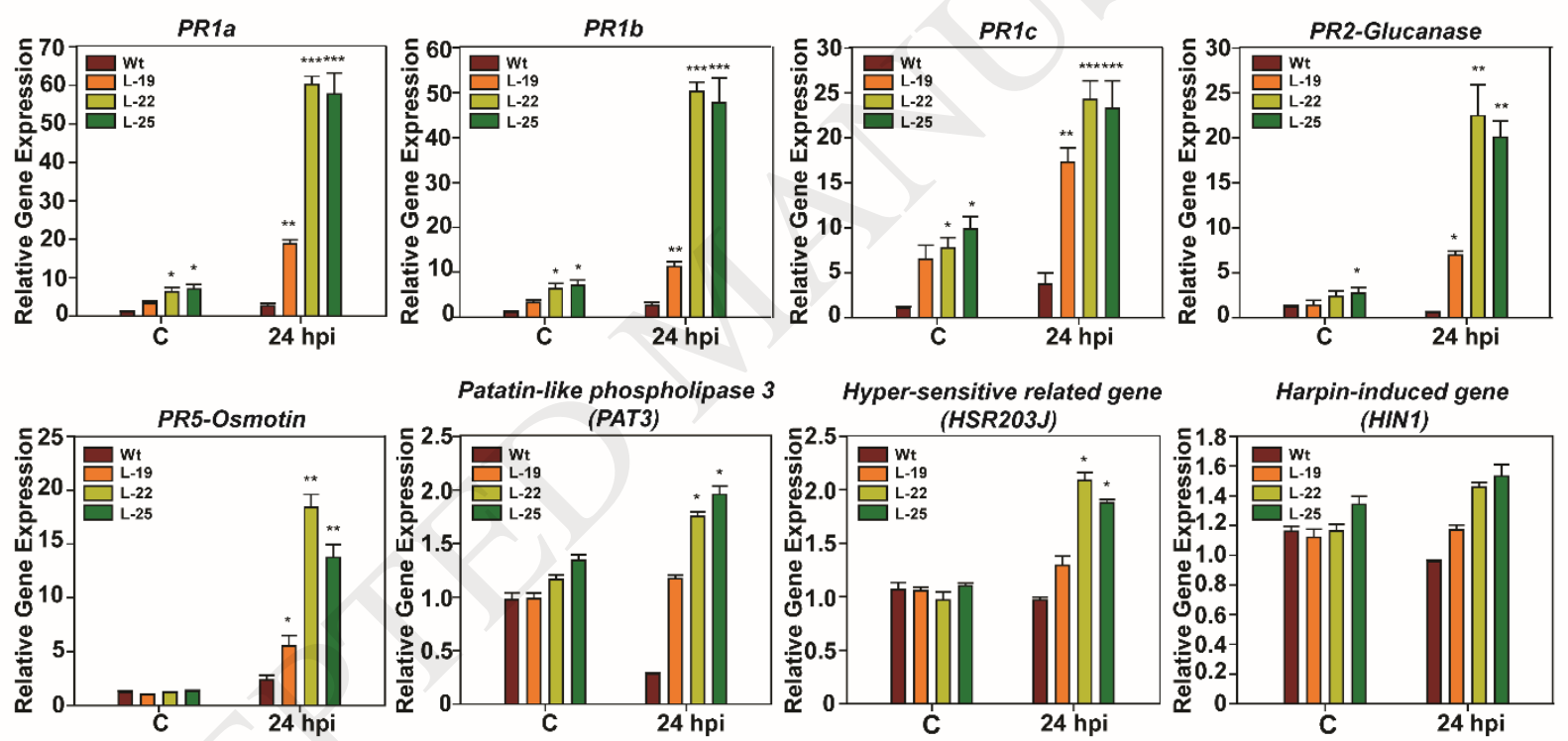
Table 1 List of the characterized DnaJ proteins in Eukaryotes.

\begin{tabular}{|c|c|c|c|c|c|c|c|}
\hline S.No. & Gene Bank ID & $\begin{array}{l}\text { DnaJ } \\
\text { Protein }\end{array}$ & Type & $\begin{array}{l}\text { MW } \\
\text { (KDa) }\end{array}$ & pI & Source & Authors \\
\hline 1 & KJ658279 & AdDjSKI & III & 39.067 & 6.05 & A. diogoi & $\begin{array}{l}\text { Present } \\
\text { study }\end{array}$ \\
\hline 2 & AAB86798.1 & ATJ1 & I & 41.471 & 9.14 & Arabidopsis thaliana & [57] \\
\hline 3 & AAB86892.1 & ATJ3 & I & 46.444 & 5.74 & Arabidopsis thaliana & {$[58]$} \\
\hline 4 & AAU06581.1 & $\mathrm{CDJ} 2$ & III & 38.4 & 9.37 & Chlamydomonas reinhardtii & [59] \\
\hline 5 & AAU06580.1 & $\mathrm{CDJ} 1$ & I & 44.99 & 9.27 & Chlamydomonas reinhardtii & {$[60]$} \\
\hline 6 & ACV53168.1 & $\mathrm{CDJ} 3$ & III & 43.111 & 8.35 & Chlamydomonas reinhardtii & {$[23]$} \\
\hline 7 & ACV53169.1 & CDJ4 & III & 41.789 & 7.03 & Chlamydomonas reinhardtii & {$[23]$} \\
\hline 8 & BAA76883.1 & pSGJ-1 & I & 47.499 & 6.99 & Salix gilgiana & {$[61]$} \\
\hline 9 & BAA76888.1 & pSGJ-2 & I & 47.499 & 6.99 & Salix gilgiana & {$[61]$} \\
\hline 10 & BAA35121.1 & pSGJ-2(1) & I & 46.563 & 6 & Salix gilgiana & {$[61]$} \\
\hline 11 & CAA47925.1 & CsDNAJ-1 & I & 58.08 & 5.37 & Cucumis sativus & {$[62]$} \\
\hline 12 & AAG48824.1 & DNAJ 8 & III & 40.048 & 5.24 & Arabidopsis thaliana & {$[63]$} \\
\hline 13 & AEE86605.1 & DnaJ 11 & III & 17.822 & 9.23 & Arabidopsis thaliana & {$[63]$} \\
\hline 14 & AEE83331.1 & DnaJ 20 & III & 23.361 & 9.61 & Arabidopsis thaliana & {$[63]$} \\
\hline 15 & NP_001154788.1 & AtDnaJ & III & 29.252 & 10.5 & Arabidopsis thaliana & {$[64]$} \\
\hline 16 & NP_001233835.1 & LeCDJ1 & III & 18.069 & 5.82 & Solanum lycopersicum & {$[55]$} \\
\hline 17 & GmHSP40.1 & GmHSP40 & III & 50.589 & 5.43 & soybean nuclear & {$[16]$} \\
\hline 18 & CAA49211.1 & ApDnaJ & $\mathrm{I}$ & 46.910 & 9.54 & Allium porrum & {$[65]$} \\
\hline 19 & BAB70509.1 & OsDjA7/8 & I & 46.910 & 9.54 & Oryza sativa & {$[66]$} \\
\hline 20 & CAA54720.1 & LDJ2 & I & 46.584 & 6.22 & Allium ampeloprasum & {$[65]$} \\
\hline 21 & NP_565533 & DnaJ & I & 47.762 & 9.25 & Arabidopsis thaliana & {$[67]$} \\
\hline 22 & AK323942.1 & $\begin{array}{l}\text { LeCDJ2/ } \\
\text { SICDJ2 }\end{array}$ & III & 32.705 & 9.3 & Solanum lycopersicum & {$[18,20]$} \\
\hline
\end{tabular}

